\title{
Targeted Therapeutic Approach Based on Understanding of Aberrant Molecular Pathways Leading to Leukemic Proliferation in Patients with Acute Myeloid Leukemia
}

\author{
Moo-Kon Song ${ }^{1}$, Byeong-Bae Park ${ }^{2, *}$ and Ji-Eun Uhm ${ }^{2}$ \\ 1 Department of Hematology-Oncology, Hanyang University Hanmaeum Changwon Hospital, \\ Changwon 51497, Korea; mksong9676@hanmail.net \\ 2 Division of Hematology-Oncology, Department of Internal Medicine, Hanyang University \\ College of Medicine, Hanyang University Seoul Hospital, Seoul 51139, Korea; jieunuhm@hanyang.ac.kr \\ * Correspondence: bbpark@hanyang.ac.kr; Tel.: +82-2-2290-8114; Fax: +82-2-2290-7112
}

check for updates

Citation: Song, M.-K.; Park, B.-B.; Uhm, J.-E. Targeted Therapeutic Approach Based on Understanding of Aberrant Molecular Pathways Leading to Leukemic Proliferation in Patients with Acute Myeloid Leukemia. Int. J. Mol. Sci. 2021, 22, 5789. https://doi.org/10.3390/ ijms22115789

Academic Editor: Yosuke Minami

Received: 18 April 2021

Accepted: 26 May 2021

Published: 28 May 2021

Publisher's Note: MDPI stays neutral with regard to jurisdictional claims in published maps and institutional affiliations.

Copyright: (C) 2021 by the authors. Licensee MDPI, Basel, Switzerland. This article is an open access article distributed under the terms and conditions of the Creative Commons Attribution (CC BY) license (https:// creativecommons.org/licenses/by/ $4.0 /)$.

\begin{abstract}
Acute myeloid leukemia (AML) is a heterogenous hematopoietic neoplasm with various genetic abnormalities in myeloid stem cells leading to differentiation arrest and accumulation of leukemic cells in bone marrow (BM). The multiple genetic alterations identified in leukemic cells at diagnosis are the mainstay of World Health Organization classification for AML and have important prognostic implications. Recently, understanding of heterogeneous and complicated molecular abnormalities of the disease could lead to the development of novel targeted therapeutic agents. In the past years, gemtuzumab ozogamicin, BCL-2 inhibitors (venetovlax), IDH 1/2 inhibitors (ivosidenib and enasidenib) FLT3 inhibitors (midostaurin, gilteritinib, and enasidenib), and hedgehog signaling pathway inhibitors (gladegib) have received US Food and Drug Administration (FDA) approval for the treatment of AML. Especially, AML patients with elderly age and/or significant comorbidities are not currently suitable for intensive chemotherapy. Thus, novel therapeutic planning including the abovementioned target therapies could lead to improve clinical outcomes in the patients. In the review, we will present various important and frequent molecular abnormalities of AML and introduce the targeted agents of AML that received FDA approval based on the previous studies.
\end{abstract}

Keywords: acute myeloid leukemia; gemtuzumab ozogamicin; BCL-2

\section{Introduction}

Acute myeloid leukemia (AML) is a group of hematological malignancies characterized by rapid and uncontrolled growth of immature white blood cells in the bone marrow (BM) [1]. The various molecular alterations identified in leukemic cells at diagnosis are the mainstay of the World Health Organization classification for AML and have important prognostic implications. Some subtypes are associated with a favorable prognosis with intensive chemotherapy. However, the clinical outcome of AML is generally poor, with a worldwide 5-year overall survival rate of just 28\% [2]. The prognosis is especially unfavorable in elderly patients, who tend to be ineligible for intensive chemotherapy; the median survival time in such patients is less than 1 year [3]. In addition, since the cytarabine and idarubicin regimen was established as the standard induction chemotherapy for AML, it has remained unchanged [4]. The regimen is of limited therapeutic efficacy in many different genetic subtypes of AML. Thus, novel effective therapies are needed for such patients.

The revolution in understanding the genetic alterations of AML that has been driven by next-generation sequencing has resulted in numerous therapeutic options against potential driver mutations such as FMS-like tyrosine kinase three-internal tandem duplication (FLT3-ITD) and isocitrate dehydrogenase (IDH) mutations [5]. The 2017 European Leukemia Net (ELN) criteria provide useful information to determine the best therapeutic 
option between conventional and novel therapies. According to the criteria, AML patients are separated into favorable, intermediate, and adverse risk groups [6]. In the GermanAustralian AML Study Group, the prognostic impact of many mutations is characterized by the combined effect of concomitant molecular abnormalities [7]. NPM1 mutation is associated with a favorable prognosis in the absence or very low allele ratio of the FLT3-ITD mutation. However, tumor protein 53 (TP53) mutation is strongly associated with adverse prognosis and mainly occurs in secondary or therapy-related AML, mostly characterized by complex cytogenetics.

The use of hypomethylation agents (HMAs) or low-dose cytarabine (LDAC) treatment options in patients unfit for intensive chemotherapy or stem cell transplantation (SCT) were recently shown to be modestly effective but not satisfactory $[8,9]$. Advancements in our understanding of the genetic basis of AML over the last decade have led to the rapid development of targeted therapies. Complicated genetic mutations in AML patients could reflect several biological diseases classified by cytogenetically and molecularly defined risk. In addition, a large amount of data about novel targeted therapies for AML have shown promising results, particularly in patients without alternative therapeutic options.

In this review, we will discuss the available clinical data on novel approved targeted therapeutic options for AML based on clinical trials conducted since 2017 that could lead to US Food Drug Administration (FDA) approval.

\section{Mutational Landscape in AML}

Leukemogenesis is a multistage process leading to clonal proliferation of abnormal blood cells derived from transformed primitive hematopoietic stem cells [10]. AML is characterized by the accumulation of immature leukemic cells in the BM or peripheral blood at the expense of the normal production of terminally differentiated blood cells. AML occurs at all ages, but incidence rates are higher in the elderly, with a median age of diagnosis of $\sim 70$ years [11].

Due to the development of diagnostic technologies for cytogenetic analysis in AML, recent in-depth analysis of data from a wide cohort clarified that the number of coding mutations per AML exome or genome is lower than in most other human cancers [12,13]. The mutations lead to the deregulation of pathways such as DNA methylation-associated genes, spliceosome-complex genes, cohesion-complex genes, chromatin-modifying genes, and signaling genes $[14,15]$. At least one driver mutation in one of these genes is present in about $96 \%$ of AML patients.

Several studies have identified various novel recurrent somatic disease alleles with biological, prognostic, and therapeutic relevance, such as mutations of the DNA methyltransferase 3A gene (DNMT3A) and IDH 1/2 [16-19]. Other findings also indicate that AML is a complex and dynamic neoplasm with multiple somatically acquired driver mutations and coexisting competing clones and that the disease evolves over time [20-22]. Together, these results imply that molecular analysis could be used to predict a patient's prognosis and thus has an important role in AML patient management.

The most frequent genetic mutations in AML are summarized in Table 1. Although NPM1 mutation is associated with a good prognosis in AML patients who receive standard therapy, DNMT3A or FLT3-ITD mutations could counteract the prognostic significance of NPM1 mutations [23]. However, FLT3-ITD with a low allelic ratio may not influence the clinical impact of NPM1 mutation.

In addition, TP53 mutation is strongly indicative of adverse prognosis in AML and is mostly characterized by secondary AML patterns and complex cytogenetics [15]. In this review, we will discuss the most important molecular mutations, such as CD33, FLT3ITD, BCL2, and IDH1/2 mutations and aberrant hedgehog signaling, and the associated targeted approaches in patients with AML, along with the US FDA approval status of each approach. 
Table 1. Mutational landscape in acute myeloid leukemia.

\begin{tabular}{|c|c|c|c|c|}
\hline Mutation & $\begin{array}{l}\text { Frequency of } \\
\text { CN-AML }\end{array}$ & Mechanism of Action & Clinical Impact & Agents \\
\hline NPM1 & $30-43 \%$ & Nucleolar component & Favorable & NA \\
\hline DNMT3A & $34 \%$ & De novo DNA methylation & ND & NA \\
\hline FLT3-ITD & $28-34 \%$ & FLT3 receptor tyrosine kinase & $\begin{array}{c}\text { Unfavorable } \\
\text { in high ratio }(\geq 0.5)\end{array}$ & $\begin{array}{l}\text { Midostaurin, Sorafenib, } \\
\text { Quizartinib, Gilteritinib }\end{array}$ \\
\hline FLT3-TKD & $11-14 \%$ & FLT3 receptor tyrosine kinase & Neutral & Quizartinib, Gilteritinib \\
\hline IDH1/2 & $15-30 \%$ & Conversion of isocitrate to $\alpha$-ketoglutarate & Favorable & Ivosidenib, Enasidenib \\
\hline TET2 & $10 \%$ & $\begin{array}{c}\text { Conversion of 5-methylcytosine to } \\
\text { 5-hydroxy-methylcytosine (methylation) }\end{array}$ & ND & NA \\
\hline ASXL1 & $5-16 \%$ & $\begin{array}{l}\text { Epigenetic regulation by interaction with } \\
\text { PRC2 }\end{array}$ & Unfavorable & NA \\
\hline CEBPA & $10-18 \%$ & Hematopoietic transcription factor & Favorable & NA \\
\hline RAS & $\begin{array}{l}25 \% \text { NRAS, } \\
15 \% \text { KRAS }\end{array}$ & $\begin{array}{l}\text { G-protein associated with receptor tyrosine } \\
\text { kinase }\end{array}$ & Neutral & Cabimetinib \\
\hline KIT & $\begin{array}{l}20-30 \% \text { of } \\
\text { CBF-AML }\end{array}$ & Receptor tyrosine kinase for stem cell factor & Unfavorable & Dasatinib, Imatinib \\
\hline KMT2A-PTD & $5-10 \%$ & $\begin{array}{l}\text { abrogation of KMT2A transactivation } \\
\text { and histone methyltransferase function }\end{array}$ & Unfavorable & NA \\
\hline RUNX1 & $5-13 \%$ & Hematopoietic transcription factor & Unfavorable & NA \\
\hline ТP53 & $5-20 \%$ & Tumor-suppressor gene & Unfavorable & Idasanutlin \\
\hline
\end{tabular}

Abbreviations: NPM1, nucleophosmin 1; DNMT3A, DNA methyltransferase 3 alpha; FLT3-ITD, FMS-like tyrosine kinase 3-internal tandem duplication; IDH, isocitrate dehydrogenase; TET2, Tet methylcytosine dioxygenase 2; ASXL1, ASXL transcriptional regulator 1; CEBPA, CCAAT enhancer binding protein alpha; RAS, rat sarcoma; KMT2A, K-specific methyltransferae 2A; RUNX1, RUNXX family transcription factor 1; TP53, tumor protein 53; ND, not defined; NA, no agent.

\section{Anti-CD33 Directed Antibody Mechanism of Action}

Gemtuzumab ozogamicin (GO) is a CD33-directed antibody-drug conjugate (ADC) composed of h67.6, a CD33-directed monoclonal antibody, covalently linked to the cytotoxic agent $\mathrm{N}$-acetyl $\gamma$ calicheamicin [24]. The efficacy of GO is associated with the ubiquitous nature of CD33 as a potent target for immunotherapeutic options for AML. CD33 inhibits cell signaling by recruiting SHP-1 and 2 upon phosphorylation of tyrosine residues located within the immune-receptor tyrosine-based inhibitory motif domain on the cytoplasmic tail of the protein [25]. CD33 is internalized when it engages with antibodies. Notably, the activity of GO is derived from internalization of the ADC after successful binding of the monoclonal antibody to the immunoglobulin (Ig) V domain of CD33 on the surface of leukemic cells (Figure 1) [26].

Calicheamicin is a potent antitumor antibiotic from Micromonospora echinospora that is responsible for the cytotoxic activity of GO [27]. Once the GO-CD33 complex is internalized, the acidic lysosomal interior hydrolyzes the disulfide bond connecting calicheamicin to the acid-labile linker of GO, releasing free calicheamicin into the cell [24]. After the GO-CD33 complex is internalized, which occurs rapidly, the complex is routed to the lysosomes of the cytoplasm. In the acidic environment of the lysosome, the butanoic acid linker is hydrolyzed, releasing the toxic moiety of GO. The calicheamicin derivative is reduced by glutathione into a highly reactive species, which induces simple and double-stranded DNA breaks, resulting in DNA damage [28]. Then, the downstream DNA repair pathway is activated through the ataxia-telangiectasia mutated (ATM)/ataxia-telangiectasia and Rad3-related (ATR) and DNA-dependent protein kinase pathways and ATM/ATR proteins phosphorylate $\mathrm{CHK} 1 / \mathrm{CHK} 2$ proteins, leading to G2M cell cycle arrest. ATM/ATR are two leading proposed DNA damage response pathways that are activated as a result of these breaks, leading to apoptosis of leukemic cells [29-31]. 


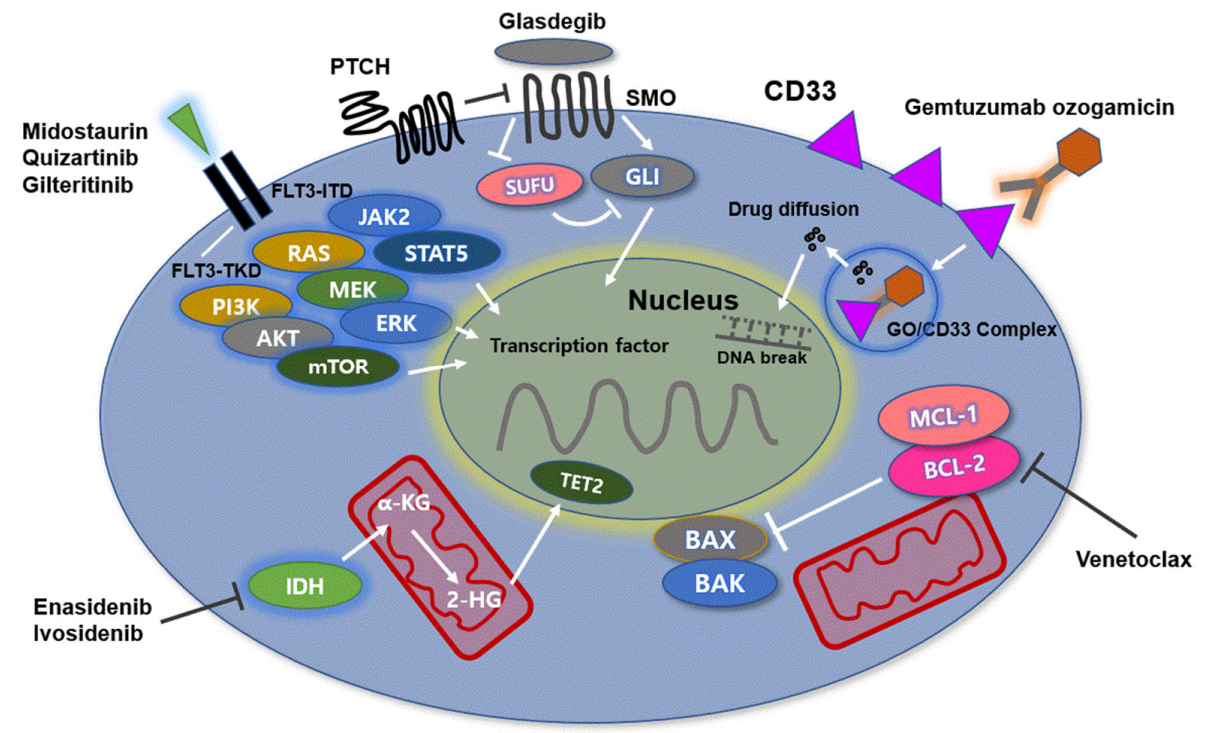

Figure 1. The molecular mechanisms of AML: Molecular dysregulation alters the expression profile of genes such as CD33, IDH1/2, FLT3, and BCL-2. The activity of gemtuzumab ozogamicin (GO) is derived from internalization of the CD33-GO complex after successful binding of the monoclonal antibody on the surface of leukemic cells, leading to apoptosis of leukemic cells. FLT3 mutations stimulate downstream signaling through JAK2/STAT5, PI3K/AKT/mTOR, and RAS/MEK/ERK. AML cells with FLT3-ITD mutations have a high genetic instability due to DNA double-strand breaks and are associated with poor clinical outcomes. Midostaurin, quizartinib, and gilteritinib effectively inhibit FLT3-ITD mutations. IDH1/2 mutation leads to reduction of $\alpha$-ketoglutarate to R2-hydroxyglutarate (R2-HG) as an oncometabolite. IDH inhibitors inhibit production of R2-HG and thus block proliferation of leukemic cells. BCL-2 and MCL-1 prevent apoptosis of leukemic cells by regulating effector proteins such as BAX and BAK as cell death mediators. The native BH3-only protein venetoclax binds to BCL-2, thereby relieving the constraints on BAX/BAK activation and initiating apoptosis. The HH/GLI signaling pathway is associated with hematopoietic stem cell function. In leukemia cells, the signaling pathway is involved in resistance of AML cells to chemotherapy. Glasdegib effectively inhibits the HH/GLI signaling pathway by binding to SMO. Abbreviations: IDH, isocitrate dehydrogenase; FLT3, FMS-like tyrosine kinase 3; BCL-2, B-cell lymphoma-2; JAK2/STAT5, Janus kinase 2/signal transducer and activator of transcription 5; PI3K/AKT/mTOR, phosphoinositide 3-kinase/Akt/mechanistic target of rapamycin; RAS/MEK/ERK, rat sarcoma/rapidly accelerated fibrosarcoma/extracellular signal-regulated kinase; ITD, internal tandem duplication; HH/GLI, hedgehog/glioma-associated oncogene homolog; AML, acute myeloid leukemia.

\section{Gemtuzumab Ozogamicin, Anti-CD33 Antibody}

\subsection{Clinical Data}

GO initially received accelerated FDA approval in 2000 based on phase II clinical trial data. The trial revealed a benefit of GO as a single agent in patients over the age of 60 with CD33+ AML at a dose of $9 \mathrm{mg} / \mathrm{m}^{2} /$ day on days 1 and 14 [32]. The data showed an objective response rate (ORR) of $30 \%$ and a complete response (CR) rate of $16.2 \%$. In the 2004 post-approval phase III trial SWOG S0106 study, patients were randomized to receive either standard induction with daunorubicin $\left(60 \mathrm{mg} / \mathrm{m}^{2} /\right.$ day on days 1,2 , and 3$)$ and cytarabine (100 mg/m² / day from days $1-7)(D A)$ or a GO-containing induction with lower doses of daunorubicin (45 mg/m² $/$ day on days 1,2 , and 3), cytarabine $\left(100 \mathrm{mg} / \mathrm{m}^{2}\right.$ from days $1-7)$ and GO (6 mg/m² on day 4; DA + GO) [33]. The addition of GO did not show a clinical benefit but was associated with an increased early mortality rate. Interestingly, DA combined with GO improved relapse-free survival (RFS) among patients in the favorable cytogenetic risk group (hazard ratio [HR]; $0.49 ; p=0.043$ ).

In Table 2, the phase III MRC AML15 trial enrolled 1113 patients younger than 60 years of age, who were randomized to receive a lower dose $\left(3 \mathrm{mg} / \mathrm{m}^{2}\right)$ of GO in induction 1 and in consolidation, in addition to the standard or other experimental treatments $[34,35]$. The study had three different induction arms, including ADE, DA, and Ida/FLAG. Overall, the addition of GO was well tolerated without a substantial increase in toxicity. However, based on the original GO randomization scheme, the addition of GO was not associated 
with improved outcomes. The only patients who benefitted from GO therapy were those with favorable karyotypes. Meanwhile, the group with intermediate or high cytogenetic risk showed no significant survival benefits.

Table 2. Clinical trials on novel targeted therapies for acute myeloid leukemia patients.

\begin{tabular}{|c|c|c|c|}
\hline Author (Refer.) & Therapeutic Schedule & Phase/Population & Clinical Outcome \\
\hline \multicolumn{4}{|c|}{ Anti-CD33 monoclonal antibody } \\
\hline Petersdorf et al. & $\begin{array}{c}\mathrm{GO}-6 \mathrm{mg} / \mathrm{m}^{2} \text { on day } 4 . \\
\text { additional } 3 \text { doses, } \\
5 \mathrm{mg} / \mathrm{m}^{2} \text { in } \mathrm{CR} \text { patients after } \\
\text { consolidation } \\
\mathrm{GO}+\text { modified DA vs. } \\
\text { standard DA }\end{array}$ & $\begin{array}{l}\text { Phase III, ND AML, } \\
\quad n=595\end{array}$ & $\begin{array}{c}\text { ORR, } 76 \% \text { in DA plus GO group vs. } 74 \% \text { in } \\
\text { DA alone } \\
(p=0.36) \\
\text { CR, } 69 \% \text { vs. } 70 \%(p=0.69) \\
5 \text {-yr RFS, } 47 \% \text { vs. } 42 \%(p=0.87) \\
5 \text {-yr OS, } 46 \% \text { vs. } 50 \%(p=0.09)\end{array}$ \\
\hline $\begin{array}{l}\text { Castaigne et al. } \\
\text { ALFA-0701 }\end{array}$ & $\begin{array}{l}\mathrm{DA}+/- \\
\mathrm{GO}-3 \mathrm{mg} / \mathrm{m}^{2} \text { for day } 1,4, \\
\text { and } 7 \text { of induction, } \\
3 \mathrm{mg} / \mathrm{m}^{2} \text { for day } 1 \text { of two } \\
\text { consolidations }\end{array}$ & $\begin{array}{l}\text { Phase III, ND AML, } \\
\qquad n=278\end{array}$ & $\begin{array}{l}\text { CR/CRi, } 81 \text { in GO + group vs. } 75 \% \text { in } \\
\text { GO-group }(p=0.25) \\
\text { 2-yr EFS, } 40.8 \text { vs. } 17.1 \%(p=0.0003) \\
\text { 2-yr OS, } 53.2 \text { vs. } 41.9 \%(p=0.0368) \\
\text { 2-yr RFS, } 50.3 \text { vs. } 22.7 \%(p=0.0003) \\
\text { Survival benefit-favorable and } \\
\text { intermediate-risk group }\end{array}$ \\
\hline $\begin{array}{l}\text { Burnett et al. } \\
\text { MRC-AML15 }\end{array}$ & $\begin{array}{c}\text { GO-3 mg } / \mathrm{m}^{2} \text { for day } 1 \\
+\mathrm{DA}, 2 \text { cycles, FLAG-ida or } \\
\text { ADE }\end{array}$ & $\begin{array}{l}\text { Phase III, ND AML, } \\
n=1113\end{array}$ & $\begin{array}{l}\text { Addition of GO—no different in OS, RFS, } \\
\text { and TRM. } \\
\text { But, OS } \uparrow \text { in favorable cytogenetic risk (79 vs. } \\
51 \%, p=0.0003 \text { ) }\end{array}$ \\
\hline $\begin{array}{l}\text { Burnett et al. } \\
\text { NCRI-AML16 and LRF } \\
\text { AML } 14\end{array}$ & $\begin{array}{l}\mathrm{GO}-3 \mathrm{mg} / \mathrm{m}^{2} \text { for day } 1 \\
+\mathrm{DA} \text { or DC (daunorubicin }+ \\
\quad \text { claforabine, } \mathrm{D} 1-5)\end{array}$ & $\begin{array}{l}\text { Phase III, ND AML, } \\
n=1115\end{array}$ & $\begin{array}{c}\text { IC- } \uparrow \text { RFS ( } 28 \text { vs. } 23 \%, p=0.03) \text { and } \uparrow \mathrm{CR}(35 \\
\text { vs. } 29 \text { and, } p=0.04) \\
\text { Non-IC- } \uparrow \text { ORR }(17 \text { vs. } 30 \%, p=0.006) \text { and } \uparrow \\
\text { CR ( } 11 \text { vs. } 21 \%, p=0.002) \\
\text { But, no improvement of OS }\end{array}$ \\
\hline $\begin{array}{l}\text { Burnett et al. } \\
\text { NCRI-AML17 }\end{array}$ & $\begin{array}{c}\mathrm{GO}-3 \mathrm{mg} \text { or } 6 \mathrm{mg} / \mathrm{m}^{2} \text { for } \\
\text { day } 1 \\
+ \text { DA or ADE (DA + } \\
\text { etoposide) }\end{array}$ & $\begin{array}{l}\text { Phase III, ND AML, } \\
n=788\end{array}$ & $\begin{array}{l}\text { Significant higher CR rate in } 3 \mathrm{mg} \text { GO group } \\
\text { vs. } 6 \text { mg group }(p=0.03) \\
6 \text { mg group-higher } 30 \text { and } 60 \text {-day TRM ( } p= \\
0.02 ; p=0.01)\end{array}$ \\
\hline $\begin{array}{l}\text { Delaunay et al. } \\
\text { GEOLAMS-AML } 2006 \\
\text { IR }\end{array}$ & $\mathrm{GO}-6 \mathrm{mg} / \mathrm{m}^{2}$ for day $1+\mathrm{DA}$ & $\begin{array}{l}\text { Phase III, ND AML, } \\
\qquad n=238\end{array}$ & $\begin{array}{c}\text { CR-not different between GO + vs. GO- } \\
\text { group } \\
\text { (91.6 vs. } 86.5 \%, p=\mathrm{NS}) \\
\text { EFS, OS-not different between GO + vs. } \\
\text { GO- group.VOD, hepatotoxicity, higher in } \\
\text { GO + group ( } 23 \text { vs. } 13 \% ; p=0.031)\end{array}$ \\
\hline $\begin{array}{l}\text { Burnett et al. } \\
\text { EORTC-GIMEMA } \\
\text { AML } 19\end{array}$ & $\begin{array}{l}\mathrm{GO}-6 \mathrm{mg} / \mathrm{m}^{2} \text { for day } 1,3 \\
\mathrm{mg} / \mathrm{m}^{2} \text { for day } 8 \\
\text { vs. Best supportive care } \\
\text { Combination stud }\end{array}$ & $\begin{array}{l}\text { Phase III, ND AML } \\
\text { unfit for IC, } \\
\qquad n=237 \\
\text { with hypomethylatin }\end{array}$ & $\begin{array}{c}\text { OS, } 4.9 \text { months in GO group vs. } 3.6 \text { months } \\
\text { BSC group ( } p=0.005) \\
\text { 1-yr OS, } 24.3 \% \text { vs. } 9.7 \% \\
\text { OS benefit of GO, higher in women and } \\
\text { favorable, intermediate-risk group. } \\
\text { CR + CRi in GO group, } 27 \% \\
\text { agents }\end{array}$ \\
\hline $\begin{array}{l}\text { DiNardo et al. } \\
\text { Blood } 2019\end{array}$ & $\begin{array}{l}\text { Venetoclax, 400, 800, } 1200 \text { mg } \\
\text { + HMAs (AZA, or DEC) }\end{array}$ & $\begin{array}{c}\text { ND AML } \geq 60 \text { years } \\
\text { or unfit for IC } \\
n=145\end{array}$ & $\begin{array}{c}\text { CR/CRi, } 67 \% \text { in all patients; } \\
\text { CR/CRi, } 73 \% \text { in venetoclax } 400 \mathrm{mg} / \text { day } \\
\text { group } \\
\text { Median CR/CRi duration, } 11.3 \text { months } \\
\text { Median OS, } 17.5 \text { months }\end{array}$ \\
\hline
\end{tabular}


Table 2. Cont.

\section{BCL-2 inhibitor}

$\begin{array}{cc}\text { DiNardo et al. } & \text { Venetoclax, } 400 \mathrm{mg} / \text { day }+ \\ \text { NEJM } 2020 & \text { AZA }\end{array}$
Phase III, $\geq 75$ years or unfit for IC, $n=431$

OS, 14.7 months in venetoclax-AZA group vs. 9.6 months in control $(p<0.001)$

$\mathrm{CR} / \mathrm{CRi}, 36.7 \% / 66.4 \%$ in venetoclax-AZA group

vs. $17.6 \% / 28.3 \%$ in control $(p<0.001)$

\section{Combination study with Low dose cytarabine}

Median age, 74 yrs (range, 63-90 yrs) In enrolled patients

Wei et al. (JCO) Venetoclax, $600 \mathrm{mg} /$ day + LDAC
CR/CRi, 54\%; OS, 10.1 months; DOR, 8.1 months

In patients without prior HMA exposure,

CR/CRi, 62\%; DOR, 14.8 months; OS, 13.5 months

Median age, 76 yrs (range, 36-93 yrs)

OS, 8.4 mos in venetoclax + LDAC vs. 4.1 mos in LDAC alone $(p=0.04)$.

CR/CRi, $48 \%$ in venetoclax + LDAC vs. $13 \%$ in LDAC alone $(p<0.001)$

\section{FLT3 inhibitor}

\section{Midostaurin}

Stone et al.

Stone et al.

DA + / - Midostaurin, 50 $\mathrm{mg} /$ day twice/day
Phase Ib, ND AML, $n=29$

CR, 92\% in FLT3-ITD + vs. 74\% in FLT3-WT $(p=\mathrm{NS})$

1 and 2-yr OS, 0.85, 0.62 in FLT3-ITD+ vs. $0.78,0.52$ in FLT3-WT $(p=$ NS)

1 -yr DFS, 50 in FLT3-ITD+ vs. $60 \%$ in FLT3-WT ( $p=$ NS)

OS, 74.7 in midostaurin, higher than 25.6 months in placebo $(p=0.009)$

EFS, in midostaurin group, higher than

placebo $(p=0.002)$
$\mathrm{CR}, 58.9$ in midostaurin vs. $53.5 \%$ in placebo $(p=\mathrm{NS})$.

Midostaurin, beneficial in both ITD and TKD mutation

Severe toxicity, similar between two groups $(p=\mathrm{NS})$

\section{Quizartinib}

Cortes et al. (JCO) quizartinib, escalating doses of 12 to $450 \mathrm{mg}$ / day
Phase I, R/R AML
$+/-$ FLT3 status,
$n=76$

Phase II cohort, R/R AML, $n=333$

Cortes et al. (lancet) quizartinib monotherapy
Cohort $1 \geq 60$ yrs,

$\mathrm{R} / \mathrm{R}$ within $1 \mathrm{yr}$

Cohort $2 \geq 18$ yrs,

$\mathrm{R} / \mathrm{R}$ after salvage or SCT
In enrolled patients-ORR/CR-30\%/13\%

ORR-53\% in FLT3-ITD group vs. 14\% FLT3-WT group

Cohort 1

Composite CR/CR-56\%/3\% in FLT3-ITD group

Compositive CR/CR-36\%/5\% in FLT3-WT group Cohort 2

Composite CR/CR-46\%/4\% in FLT3-ITD group

Compositive CR/CR-30\%/3\% in FLT3-WT group 
Table 2. Cont.

\begin{tabular}{|c|c|c|c|}
\hline Cortes et al. & $\begin{array}{l}\text { quizartinib vs. investigator's } \\
\text { choice }\end{array}$ & $\begin{array}{l}\text { Phase III, } \\
\text { R/R AML with } \\
\text { FLT-ITD +, } \\
n=367\end{array}$ & $\begin{array}{c}\text { OS, } 6.2 \text { in quizartinib vs. } 4.7 \text { months in } \\
\text { chemotherapy }(p=0.02) \\
\text { Therapy-related death, } 17 \% \text { vs. } 17 \%(p=\text { NS) }\end{array}$ \\
\hline \multicolumn{4}{|c|}{ Gilteritinib } \\
\hline & $\begin{array}{l}\text { gilteritinib, } 120 \mathrm{mg} / \text { day vs. } \\
\text { salvage chemotherapy }\end{array}$ & $\begin{array}{l}\text { Phase III, } \\
\text { R/R AML with } \\
\text { FLT-ITD +, } \\
n=371\end{array}$ & $\begin{array}{c}\text { OS, } 9.3 \text { in gilteritinib vs. } 5.6 \text { months in } \\
\text { chemotherapy }(p<0.001) \\
\text { EFS, } 2.8 \text { months vs. } 0.7 \text { months }(p=\mathrm{NS}) . \mathrm{CR} \\
\text { with hematologic recovery, } 34.0 \text { vs. } 15.3 \% \\
(18.6,95 \% \mathrm{CI} ; 9.8-27.4)\end{array}$ \\
\hline \multicolumn{4}{|c|}{ IDH1/2 inhibitor } \\
\hline \multicolumn{4}{|c|}{ Enasidenib } \\
\hline Stein et al. & $\begin{array}{c}\text { Dose-escalation phase, } 50-650 \\
\text { mg/day/day } \\
\text { Expansion phase, } 100 \\
\text { mg/day.day }\end{array}$ & $\begin{array}{l}\text { Phase I/2, R/R AML, } \\
\qquad n=214\end{array}$ & $\begin{array}{c}\text { Median age, } 68 \text { years. } \\
\text { ORR/CR-38.8\%/ } 19.6 \% \\
\text { BMT proceeding rate- } 10.3 \% \\
\text { Medians OS, } 8.8 \text { months } \\
\text { RBC/PLT transfusion } \\
\text { independence- }-40.2 \% / 43.1 \%\end{array}$ \\
\hline Klink et al. & $\begin{array}{l}\text { Enasienib, } 50-650 \\
\text { mg/day/day } \\
\text { Control group—other } \\
\text { treatment group }\end{array}$ & $\begin{array}{c}\text { Retrospective, R/R } \\
\text { AML, } \\
n=200\end{array}$ & $\begin{array}{r}\text { Enasidenib, less refractory to induction than } \\
\text { control group }(p=0.02) \\
\text { CR/PR/LFS, enasidenib group, higher than } \\
\text { control }(p<0.01) \\
\text { Median PFS, } 8.4 \text { vs. } 4.8 \text { months }(p=<0.01) \\
\text { Median OS, } 11.0 \text { vs. } 6.4 \text { months }(p<0.01)\end{array}$ \\
\hline Riva et al. & $\begin{array}{l}\text { Enasidenib, } 100 \mathrm{mg} / \text { day / day } \\
\text { Control group-other } \\
\text { treatment group }\end{array}$ & $\begin{array}{c}\text { Retrospective, } \mathrm{R} / \mathrm{R} \\
\text { AML } \\
n=37\end{array}$ & $\begin{array}{c}\text { Median OS in enasidenib, higher than } \\
\text { control }(p=0.0419) \\
\text { PFS ( } p=\text { NS) }\end{array}$ \\
\hline
\end{tabular}

\section{Ivosidenib}

DiNardo et al. $\quad$ ivosidenib $500 \mathrm{mg} / \mathrm{d} \quad \begin{gathered}\text { Phase I, R/R AML, } n \\ =125\end{gathered}$

Median follow-up duration, 14.8
monthsORR/CRh/CR-41, 30, $22 \%$
Duration of ORR/CRh/CR-6.5/8.2/9.3 months

In F/U 14.8 months, median OS 8,8 months

OS, 8.1 in ivosidenib vs. 2.9 months control

Ivosidenib, $500 \mathrm{mg} /$ day

Paschka et al.
Control group-other treatment group
Data analysis, $\mathrm{R} / \mathrm{R}$ AML, $n=434$ group $(p<0.0001)$

$6 / 12$-month survival rate- $55.7 \% / 35.0$ vs. $29.1 \% / 10.8 \%(p<0.001)$

CR-18.3\% vs. $7.0 \%(p<0.001)$

Hedgehog signaling inhibitor

\section{Glasdegib}

Cortes et al.

Glasdegib, 100 mg + LDAC vs. LDAC alone
Phase II, ND AML unfit for IC, $n=132$
Median OS was 8.8 months with glasdegib group

vs. 4.9 months with LDAC group $(p=0.0004)$

$\mathrm{CR}, 17 \%$ in gladegib group vs. $2.3 \%$ in LDAC group $(p<0.05)$

Grade $\geq 3$ AE, pneumonia (16.7\%), fatigue (14.3\%)

\footnotetext{
Abbreviations: GO, gemtuzimab ozogamicin; CR, complete response; ND AML, newly diagnosed acute myeloid leukemia; ORR, overall response rate; DA, daunorubicin and anthracycline; RFS, relapse-free survival; OS, overall survival; IC, intensive chemotherapy; VOD, veno-occlusive disease; $\mathrm{CRi}$, morphologic complete remission with incomplete blood count recovery; LDAC, low dose cytarabine; DOR, duration of response.
}

In contrast, the ALFA-0701 simple single open-label phase III study investigated the efficacy of a fractionated dose of $\mathrm{GO}, 3 \mathrm{mg} / \mathrm{m}^{2}$, in addition to standard induction chemotherapy in newly diagnosed de novo AML patients [36]. The patients were ran- 
domized to receive standard DA therapy or DA combined with GO therapy. GO was administered at $3 \mathrm{mg} / \mathrm{m}^{2}$ on days 1,4 , and 7 during induction therapy. The rates of remission $(81 \%$ vs. $75 \%, p=0.25)$ and 3 -year OS (38\% vs. $36 \%, p=0.18)$ were not significantly improved in the GO group, while 3-year event-free survival (EFS; 31 vs. 19\%, $p=0.0026$ ) and 2-year RFS (38 vs. $25 \% p=0.006$ ) significantly improved in the GO group.

Moreover, a meta-analysis of 3325 patients from five randomized controlled trials, the MRC AML15, SWOG S0106, NCRI AML16, GOELAMS AML 2006 IR, and ALFA-0701 trials demonstrated that the addition of GO did not increase the portion of patients achieving $\mathrm{CR} / \mathrm{CRi}$ but significantly reduced the risk of relapse and improved OS at 5 years [37]. In addition, the data showed that the low dose of GO, $3 \mathrm{mg} / \mathrm{m}^{2}$, was associated with fewer early deaths than the higher dose of $6 \mathrm{mg} / \mathrm{m}^{2}$, while the two were equally efficacious.

The NCRI AML17 trial was designed to identify the optimal dose of GO. The study patients were randomized to receive GO on day 1 of induction treatment at a dose of either 3 or $6 \mathrm{mg} / \mathrm{m}^{2}$. The CR rates were similar across both groups ( $82 \mathrm{vs} .87 \% p=0.0$ ) [38]. The ORRs were also similar ( $89 \%$ vs. $86 \%, p=0.17$ ). Moreover, the data showed that RFS and OS did not differ between the two groups $(p=0.5 ; p=0.3)$. However, the 30-day mortality $(7 \%$ vs. $3 \% p=0.02)$ and 60 -day mortality rates ( $9 \%$ vs. $5 \%, p=0.01)$ were significantly higher in the $6 \mathrm{mg} / \mathrm{m}^{2}$ group than the $3 \mathrm{mg} / \mathrm{m}^{2}$ group ( $p=0.02$ ). Moreover, the incidence of veno-occlusive disease was higher in the $6 \mathrm{mg} / \mathrm{m}^{2}$ group $(5.6 \%$ vs. $0.5 \% ; p<0.0001)$. The results revealed that there was no advantage in using a single dose of $6 \mathrm{mg} / \mathrm{m}^{2} \mathrm{GO}$ compared with $3 \mathrm{mg} / \mathrm{m}^{2}$ in combination with induction therapy. In this regard, the lower fractionated GO dosing plan seems to produce better response and survival rates in a combination setting with standard induction therapy in AML patients.

Finally, the EORTC-GIMEMA AML-19 study showed an increase in OS rate in AML patients treated with GO-containing therapy, compared to best supportive care (BSC) when patients with newly diagnosed CD33-positive AML were treated with GO monotherapy at $6 \mathrm{mg} / \mathrm{m}^{2}$ on day 1 and $3 \mathrm{mg} / \mathrm{m}^{2}$ on day 8 [39]. The patients were randomly assigned to the two groups (118 to the GO group and 119 to the BSC group). The median OS was 4.9 months (95\% CI, 4.2-6.8 months) in the GO group and 3.6 months (95\% CI, 2.6-4.2 months) in the BSC group (HR, $0.69 ; 95 \%$ CI, $0.53-0.90 ; p=0.005)$. The 1 -year OS rate was $24.3 \%$ in the GO group and $9.7 \%$ in the BSC group. The OS benefit conferred by GO was consistent across most subgroups, and was especially apparent in patients with high CD33 expression status, in those with favorable/intermediate cytogenetic risk profiles, and in women. Overall, CR was observed in 30 of 111 (27\%) patients in the GO group.

\subsection{BCL-2 Inhibitor}

\section{Mechanisms of Action}

The function of the BCL-2 protein is to prevent cellular apoptosis. Thus, overexpression of BCL-2 is significantly associated with inappropriate apoptosis, increased tumor overgrowth, and diminished sensitivity to chemotherapy [40]. In normal cells, antiapoptotic proteins such as BCL-2 and MCL-1 prevent apoptosis by constraining effector proteins (BAX and BAK) as cell death mediators. However, when cells are no longer required or undergo significant stresses, such as genotoxic damage, apoptosis is stimulated by activation of BCL-2 homology domain 3 (BH3)-only proteins such as BIM, BID, BAD, PUMA, NOKA, $\mathrm{BIK}, \mathrm{BMF}$, and HRK. These BH3-only proteins bind to and inhibit BCL-2 and MCL-1. Once BCL-2 is targeted in this manner, BAX and BAK cannot be constrained and drive cell death by causing mitochondrial damage. Since the binding of BH3-only proteins to BCL-2 or MCL-1 has a catalytic role in cell apoptosis, several substances that potently mimic their activity were developed to inhibit the activity of prosurvival proteins pharmacologically. Currently, the most advanced BH3 mimetic compound is venetoclax. Similar to the native BH3-only protein, venetoclax binds to BCL-2 with tight affinity, thereby relieving the constraint on BAX/BAK activation and initiating apoptosis (Figure 1) [41,42]. 


\subsection{Venetoclax, BCL-2 Inhibitor \\ Clinical Data}

Preclinical data demonstrated that AZA could reduce MCL-1 levels, mediating resistance to BCL-2 inhibitors. AZA primed AML cells for venetoclax-induced apoptosis via NOXA induction. Thus, AZA and venetoclax synergistically activated BAX and thus stimulated mitochondrial apoptosis in AML cells [43,44].

In Table 2, a large, multicenter, phase $\mathrm{Ib}$ dose-escalation and expansion study reported on the safety and efficacy of venetoclax with HMA in AML patients older than 65 years with treatment-naive AML who were ineligible for intensive chemotherapy [42]. During dose escalation, oral venetoclax was administered at 400,800 , or $1200 \mathrm{mg}$ daily in combination with either decitabine (DEC) $\left(20 \mathrm{mg} / \mathrm{m}^{2}\right.$, days $1-5$, intravenously [IV]) or azacytidine (AZA) $\left(75 \mathrm{mg} / \mathrm{m}^{2}\right.$, days $1-7$, IV or subcutaneously [SC]). In the expansion, 400 or $800 \mathrm{mg}$ venetoclax was given with either DEC or AZA. The median patient age was 74 years, and poor-risk cytogenetics was present in $49 \%$ of patients. In a median follow-up time of 8.9 months, the CR/CRi rates were $67 \%$ and did not differ between the AZA and DEC groups. Patients with poor-risk cytogenetics and those older than 75 years had CR/CRi rates of $60 \%$ and $65 \%$, respectively. The median time to response was 1.2 cycles (months) and the MRD negativity rate among responders was $29 \%$. With a median follow-up time of 15 months, the median duration of response (DOR) and OS were 13.1 and 17.5 months, respectively. Among patients with CR/CRi, median DOR was 11.3 months, and median OS was not reached. Although benefits were seen in all patients, outcomes differed between the molecular and cytogenetic subgroups. Accordingly, CR/CRi rates were higher in patients with NPM1 and IDH1/2 mutations (91 and 71\%, respectively) and lower in patients with TP53 mutations and poor cytogenetics (47 and 60\%, respectively). Median DOR was also longer in patients with NPM1 and IDH1/2 mutations (24.4 months) and shorter in those with FLT3 and TP53 mutations (7.2 months).

Another phase III, multicenter, randomized, double-blind, placebo-controlled trial was conducted to evaluate the efficacy and safety of AZA plus venetoclax, compared to AZA plus placebo in 431 newly diagnosed AML patients who were unfit for standard induction therapy due to coexisting comorbidities and age greater than 75 years old [45]. The patients were treated with AZA $\left(75 \mathrm{mg} / \mathrm{m}^{2} \mathrm{SC}\right.$ or IV on day $1-7,28$-day cycle) plus venetoclax (target dose, $400 \mathrm{mg}$ ) or matching placebo administered orally in 28-day cycles. The intention-to-treat population included 431 patients (286 in the AZA-venetoclax group and 145 in the AZA-placebo control group). The median age was 76 years in both groups (range, 49-91 years old). At a median follow-up of 20.5 months, the median OS was 14.7 months in the AZA-venetoclax group versus 9.6 months in the control group (hazard ratio for death, 0.66 ; $95 \% \mathrm{CI}, 0.52-0.85 ; p<0.001)$. The incidence of $\mathrm{CR}$ was also higher in the AZA-venetoclax group than in the control group (36.7\% vs. $17.9 \%$; $p<0.001)$. Moreover, the composite $\mathrm{CR}$ and DOR were higher in the AZA-venetoclax group than in the control group (composite CR, 66.4 vs. $28.3 \%, p<0.001$; DOR, 17.8 vs. 13.9 months). The incidence of any-grade important adverse events (44\% in the AZA-venetoclax group vs. $35 \%$ in the control group) and >grade 3 thrombocytopenia (45 vs. 38\%, respectively), neutropenia ( 42 vs. $28 \%$ ), febrile neutropenia ( 42 vs. $19 \%$ ) and any-grade infections ( 84 vs. $67 \%$ ) were also investigated.

A recent phase $\mathrm{Ib} / \mathrm{II}$ study also investigated the safety and preliminary efficacy of venetoclax combined with LDAC in AML patients older than 60 years old and unfit for intensive chemotherapy. In the data, venetoclax $(600 \mathrm{mg} /$ day $)$ was orally administrated in 28-day cycles, and LDAC ( $20 \mathrm{mg} / \mathrm{m}^{2}$ per day, SC) was given on days 1 to 10 [41]. The median age was 74 years (range, $63-90$ years). Overall, $29 \%$ of the patients had previously received $\mathrm{HMA}, 49 \%$ had secondary AML, and $32 \%$ had poor-risk cytogenetic features. The early mortality rate was $6 \%$. Moreover, $54 \%$ of the patients achieved CR/CRi. The median OS was 10.1 months (95\% CI, 5.7 to 14.2), and the median DOR was 8.1 months (95\% CI, 5.3 to 14.9 months). Among patients without prior HMA exposure, CR/CRi was achieved in $62 \%$ of cases, median DOR was 14.8 months, and median OS was 13.5 months 
(95\% CI, 7.0 to 18.4 months). The most common grade 3 or greater adverse events were febrile neutropenia (42\%), thrombocytopenia (38\%), and neutropenia (34\%). In addition, patients with NPM1 or IDH1/2 mutations had better outcomes (CR/CRi rate, 89 and 72\%, respectively), compared to those with TP53 or FLT3 mutations (30 and 44\%, respectively). The data showed that venetoclax plus LDAC showed a significantly improved safety profile, producing rapid and durable remission in older adults with AML ineligible for intensive chemotherapy.

In another international phase III randomized double-blind placebo-controlled trial, patients older than 18 years old with newly diagnosed AML ineligible for intensive chemotherapy were randomized $2: 1$ to receive venetoclax $(n=143)$ or placebo $(n=68)$ in 28-day cycles, plus LDAC on days 1 to 10 [46]. The median age was 76 years old (range, 36-93 years), 38\% of patients had secondary AML and $20 \%$ had received prior HMA treatment. The planned data analysis showed that venetoclax plus LDAC led to a $25 \%$ reduction in the risk of death, compared to LDAC alone, but the difference was not statistically significant (HR, 0.75; 95\% CI, 0.52-1.07; $p=0.11$ ), although median OS was 7.2 vs. 4.1 months, respectively. The unplanned analysis showed that the venetoclax arm had significantly greater OS (8.4 months; HR, 0.70; 95\% CI, 0.50-0.98; $p=0.04)$. The $\mathrm{CR} / \mathrm{CRi}$ rates were 48 and $13 \%$ in the venetoclax plus LDAC group and LDAC alone group, respectively $(p<0.001)$. The reported adverse events greater than grade 3 (venetoclax vs. LDAC alone) were febrile neutropenia (32 vs. 29\%), neutropenia (47 vs. 16\%), and thrombocytopenia (45 vs. 37\%). Venetoclax plus LDAC treatment was associated with significant improvements in response and OS, compared to LDAC alone, with a favorable safety profile.

In the abovementioned data, the efficacy of venetoclax-based chemotherapy was associated with prognosis in patients with specific cytogenetic abnormalities. In particular, patients with NPM1 and IDH 1/2 mutations treated with venetoclax-based chemotherapy had favorable median survival duration. The data suggest the utility of harnessing molecular strategies for patient selection to optimize response to venetoclax-based chemotherapy, particularly for AML patients with treatment-naïve NPM1 or IDH1/2 mutations unfit for intensive chemotherapy.

\subsection{FLT3 Inhibitors}

Mechanism of Action

FLT3 is a cytokine receptor that is exclusively expressed in hematopoietic cells and plays a role in normal hematopoietic cell proliferation and survival [47]. Two frequently encountered activating FLT3 mutations include internal tandem duplications (ITDs) in the juxtamembrane domain and point mutations in the tyrosine kinase domain (TKD), most commonly at codon D835 [48,49]. FLT3 mutations are significantly involved in the proliferation, differentiation, and apoptosis of hematopoietic cells. FLT3-ITD mutation is observed in about $25 \%$ of patients with AML, whereas FLT3-TKD is detected in $7-10 \%$ of patients [50].

The presence of ITD causes loss of this inhibitory effect, leading to activation of TKD. The loss of the inhibitory effect of FLT3 is independent of the size of the duplication within the receptor. In addition, ITD-induced FLT3 signaling is aberrant, notably involving activation of STAT5 and its downstream effector molecules including Pim-1 kinase [51]. Although both FLT3-ITD and FLT3-TKD mutations result in constitutive activation of FLT3 signaling, downstream signaling pathways differ between the two mutations [52]. FLT3-ITD stimulates FLT3 signaling through JAK2/STAT5, with PI3K/AKT/mTOR and RAS/MEK/ERK. A previous preclinical study showed that STAT5 positively regulates Pim-1, which eventually activates MTOR and MCL-1, consequently conferring resistance to AKT inhibition in the FLT3-ITD cell line [53]. In other recent data, FLT3 mutations were shown to activate STAT5, leading to Bcl-x and RAD-51 upregulation, which accounted for drug resistance. However, FLT3-TKD mutations activate AKT and ERK signaling but not STAT5 (Figure 1) [54]. 
AML cells with FLT3-ITD had a high degree of genetic instability due to both an increase in DNA double-strand breaks associated with increased generation of reactive oxygen species and error-prone DNA double-strand break repair. Thus, the mutation is associated with poor treatment outcomes and short relapse-free and overall survival rates [55]. Recently, targeting of the FLT3 mutation in AML has been investigated with numerous type I tyrosine kinase inhibitors that bind the gatekeeper domain and type II inhibitors that bind the activation loop.

\subsection{Midostaurin, FLT3 Inhibitor \\ Clinical Data}

Midostaurin is a small molecule tyrosine kinase inhibitor (TKI) that promotes direct and indirect inhibition of mutant FLT3 receptor phosphorylation [56]. It has been shown to induce cell cycle arrest and apoptosis in both FLT3-ITD and FLT3-D835Y mutant cell lines. Thus, this agent was approved by the FDA in 2017 for the treatment of AML patients with FLT3-ITD mutation [57].

A phase $\mathrm{Ib}$ trial by Stone et al. investigated the efficacy of midostaurin combined with daunorubicin and cytarabine induction therapy [58]. The CR rate associated with twicedaily administration of midostaurin $50 \mathrm{mg}$ was similar between the FLT3-ITD mutation group (92\%) and the FLT3-WT group (74\%). Moreover, the 1- and 2-year OS rates were similar in patients with FLT3-ITD mutation (0.85 and 0.62) and FLT3-WT (0.78 and 0.52).

In Table 2, a phase III RATIFY placebo-controlled study investigated use of induction and consolidation chemotherapy combined with midostaurin, followed by maintenance with midostaurin in 717 patients with newly diagnosed AML with FLT3 mutation [59]. Although there was no significant difference in CR rate between the two groups, patients treated with midostaurin achieved significantly longer EFS and OS ( $p=0.009$ and $p=0.002$, respectively). The improved OS in patients with low (0.05-0.7) and high FLT3-ITD allelic burden given midostaurin suggests that the therapeutic mechanism of action may not be solely due to FLT3 kinase inhibition but may include inhibition of multiple kinases. The clinical benefit of midostaurin was consistent in patients with both FLT3-ITD and TKD mutations, and the rate of severe toxicity was similar in the two groups. These data led to FDA approval of midostaurin in newly diagnosed AML patients with FLT3 mutation.

\subsection{Quizartinib, FLT3 Inhibitor \\ Clinical Data}

Quizartinib is a selective and potent TKI of FLT3-ITD mutation and FLT3-WT without activity on FLT3-TKD [60]. It is a selective small-molecule inhibitor as monotherapy in the R/R setting and has shown enriched responses in patients with FLT3-ITD mutations. Quizartinib is generally well tolerated, with important adverse effects greater than grade 3 including QTc prolongation, bone marrow suppression, fatigue, and hypoalbuminemia.

In a phase I study of quizartinib in 76 patients with relapsed/refractory AML irrespective of FLT3 status, the ORR was 30\%, including a 13\% CR rate of any type [61]. Importantly, responses were higher in patients with FLT3-ITD mutation, compared with FLT3-WT (ORR, 53 vs. 14\%, respectively). In patients with FLT3-intermediate/not tested status, $41 \%$ showed a response. The median response duration was 13.3 weeks. The key adverse effect of quizartinib was QTc prolongation, which occurred in $12 \%$ of patients.

A subsequent similar phase II study investigated the efficacy of quizartinib in patients with R/R AML regardless of FLT3 status [62]. The study enrolled a total of 333 patients, of which 157 were in cohort 1 , who were more than 60 years old and had R/R AML within 1 year after first-line therapy, and 176 were in cohort 2 , who were over 18 years of age and had R/R disease following salvage chemotherapy or SCT. In cohort 1, 56\% of FLT3-ITD-positive patients and 36\% of FLT3-ITD-negative patients achieved composite CR, while $3 \%$ of FLT3-ITD-positive patients and 5\% of FLT3-ITD-negative patients achieved CR. In cohort 2, 46\% of FLT3-ITD-positive patients achieved composite CR, and $4 \%$ achieved CR, while $30 \%$ of FLT3-ITD-negative patients achieved composite CR, and $3 \%$ achieved 
CR. In total, $38 \%$ of the patients died within the study treatment period, including $5 \%$ who died due to adverse effects.

The recent QuANTUM-R trial aimed to compare quizartinib monotherapy with investigator's choice such as low dose cytarabine, MEC, or a FLAG-Ida regimen in R/R AML patients with FLT3-ITD mutation [63]. The primary endpoint was OS in the intention-totreat population. The results showed that OS was superior in the quizartinib group (median, 6.2 months), compared with the chemotherapy group. The rate of treatment-emergent deaths due to adverse events in the quizartinib group (13\%) was comparable to that in the chemotherapy group (17\%). Research in a front-line setting is ongoing, in the form of a phase III trial for patients with FLT3-ITD-positive AML. However, the development of FLT3 point mutations such as the D835 mutation is associated with acquired resistance to quizartinib.

\subsection{Gilteritinib, FLT3 Inhibitor Clinical Data}

Gilteritinib is a dual selective inhibitor of FLT3 and AXL [64]. It shows potential efficacy against FLT3-ITD and D835 mutations and concurrently inhibits AXL kinase, which is associated with FLT3 inhibitor resistance. TKI is approved by the FDA as a single agent for R/R AML.

In Table 2, /II study of $252 \mathrm{R} / \mathrm{R}$ AML patients, gilteritinib was well tolerated, with $37 \%$ of patients with FLT3-ITD mutation achieving composite CR, along with $9 \%$ of patients with FLT3-WT [65]. Of the patients who received prior sorafenib therapy, $49 \%$ achieved composite CR. These findings demonstrate that gilteritinib may be able to overcome some of the acquired resistance mechanisms observed in response to preceding FLT3-TKI treatment.

Moreover, a recent phase III ADMIRAL trial randomly assigned 371 patients with relapsed or refractory FLT3-mutated AML to receive either gilteritinib $120 \mathrm{mg}$ /day or salvage chemotherapy [66]. The median OS in the gilteritinib group was significantly longer than that in the chemotherapy group (9.3 vs. 5.6 months; $p<0.001)$. The median EFS was not significantly different between the two groups ( 2.8 months in the gilteritinib group vs. 0.7 months in the chemotherapy group). The percentage of patients who achieved CR with full or partial hematologic recovery was $34.0 \%$ in the gilteritinib group and $15.3 \%$ in the chemotherapy group (risk difference, 18.6 percentage points; $95 \%$ CI, 9.8 to 27.4). The ORR was higher in the gilteritinib group than the chemotherapy group. In addition, adverse events greater than grade 3 occurred less frequently in the gilteritinib group than in the chemotherapy group; the most common events in the gilteritinib group were febrile neutropenia $(45.9 \%)$, anemia $(40.7 \%)$, and thrombocytopenia $(22.8 \%)$.

\subsection{Isocitrate Dehydrogenase Inhibitors \\ Mechanism of Action}

The isocitrate dehydrogenase (IDH) enzyme promotes the turnover of isocitrate to $\alpha$-ketoglutarate $(\alpha-\mathrm{KG})$ under normal conditions. IDH2 is localized in the mitochondria and operates within the citric acid cycle, while IDH1 promotes the same reaction within the cytoplasm [67].

IDH is a key enzyme in the Krebs cycle that catalyzes the oxidative decarboxylation of isocitrate to $\alpha$-ketoglutarate. Mutations in the catalytic domains of IDH1 $/ 2$ result in the reduction of $\alpha$-ketoglutarate to R2-hydroxyglutarate (R2-HG) as an oncometabolite [68,69]. R2-HG competitively inhibits $\alpha$-ketoglutarate-dependent enzymes, leading to DNA and histone hypermethylation, chromatin modification, and differentiation arrest of hematopoietic cells (Figure 1).

IDH mutations occur in about $20 \%$ of AML cases (5 to $13 \%$ IDH1 and 8 to $17 \%$ IDH2 mutations) [70-73]. IDH mutations are more frequently identified in older patients, intermediate-risk patients, and those with higher platelet counts, increased BM counts, or with FLT3-ITD and NPM1 mutations [14,74]. The frequency of IDH mutations increases to $10-20 \%$ at the time of leukemic transformation and are often seen with DNMT3A, ASXL1, 
and SRSF2 co-mutations [75]. Allosteric IDH inhibitors such as enasidenib and ivosidenib effectively suppress the production of R2-HG, leading to a reduction in the proliferation of leukemic cells [76,77].

\subsection{Enasidenib, IDH2 Inhibitor Clinical Data}

Enasidenib is a bivalent inhibitor of R140Q and R172K mutated IDH2 and is the first IDH mutation-specific inhibitor [78,79]. It promotes the terminal differentiation of myeloid blasts into neutrophils in vivo.

A phase $1 / 2$ study evaluated enasidenib doses of 50 to $650 \mathrm{mg} / \mathrm{d}$ in 239 patients with mutant-IDH2 AML [80]. In the study, the median age was 68 years old, ORR was $38.8 \%$ (95\% CL 32.2-45.7), and CR rate was 19.6\%. Median OS was 8.8 months (95\% CI, 7.7-9.6) and response and survival were comparable between the IDH2-R140 group and IDH2R172 mutation group. Red blood cell transfusion-independence was achieved in $43.1 \%$ of patients, and platelet transfusion-independence was achieved in $40.3 \%$. The magnitude of 2-HG reduction was associated with CR in IDH2-R172 patients. Clearance of mutant-IDH2 clones was also associated with the achievement of CR. These data suggest that molecular remission is correlated with CR. The most common grade 3 or 4 treatment-related adverse events were hyperbilirubinemia (10\%), thrombocytopenia (7\%), and IDH differentiation syndrome (6\%). Enasidenib was well tolerated and induced molecular remission and hematologic responses in patients with AML for whom prior treatments had failed. In the molecular analysis, the response was associated with a reduction in IDH2 allele burden and molecular clearance. However, clearance of specific co-mutations, such as KRAS, NRAS, or FLT3 mutations, was associated with a poor response rate. FDA approval of enasidenib was granted based on the above data in R/R AML patients with IDH2 mutations.

Another recent retrospective study investigated real-world outcomes among a large cohort of patients with R/R AML with IDH2 mutations treated with enasidenib or other systemic therapies in the first $R / R$ setting [81]. Of the 124 patients in the enasidenib group and 76 in the control group, $52 \%$ and $55 \%$ were male $(p=0.62)$, and the median age in the R/R setting was 68 and 63 years $(p=0.04)$, respectively (Table). The proportion of patients with European Cooperative Oncology Group performance status (ECOG PS) $\geq 2(52 \%$ vs. $53 \%)$ and poor cytogenetic risk ( $29 \%$ vs. $29 \%)$ were similar between the two groups. Approximately $23 \%$ of patients in the enasidenib group were refractory to induction therapy, versus $40 \%$ in the control group $(p=0.02)$. The $\mathrm{CR} / \mathrm{PR} / \mathrm{morphologic}$ LFS rate was higher among patients treated with enasidenib than the control group $(77 \%$ vs. $52 \% ; p<0.01$ ). After a median follow-up duration of 9 and 6 months in the enasidenib group and control group, median PFS was 8.4 and 4.8 months (adjusted $\mathrm{HR}=0.36,95 \% \mathrm{CI}$ $0.23-0.57 ; p<0.01$ ), and median OS was 11.0 and 6.4 months (adjusted HR $=0.37,95 \%$ CI $0.22-0.60 ; p<0.01)$, respectively. The results showed that superior response rate, PFS, and OS were observed in the enasidenib group, compared with the control group treated with other therapies.

In addition, a retrospective single-center study on the use of enasidenib in R/R AML patients with IDH2 mutations analyzed outcomes in nine IDH2-mutated patients: four $(44 \%)$ cases of de novo AML and five (56\%) of secondary AML. The control group consisted of 28 patients [82]. The median age at relapse was 71 years old (range, 47-79 years). Median OS in the enasidenib group was 28 months from diagnosis (range, 3-65 months), and 15 months from treatment (range 1-27). Median PFS was 13 months (range 1-14). Among the 28 patients in the control group, median OS was 14 months (range 7-62 months) and OS from the last relapse was 2 months (range 0.5-26 months). The ENA patient group showed a significantly better OS than the control population $(p=0.0419)$. The data also demonstrated that the drug is generally well tolerated.

The addition of enasidenib to induction, consolidation, and maintenance therapy for patients with newly diagnosed AML patients with IDH2 mutations is currently being evaluated in the randomized phase 3 trials. 


\subsection{Ivosidenib, IDH1 Inhibitor \\ Clinical Data}

Ivosidenib is a potent and selective IDH1 mutation inhibitor that has shown promising results in phase 1 trials [83]. Overall, 258 patients received ivosidenib, and safety outcomes were assessed. There were $125 \mathrm{R} / \mathrm{R}$ patients in the primary efficacy population, and the median follow-up duration was 14.8 months. The rate of $\mathrm{CR}$ or $\mathrm{CR}$ with partial hematologic recovery was $30.4 \%(95 \% \mathrm{CI}, 22.5-39.3)$, the CR rate was $21.6 \%$ (95\% CI, 14.7-29.8), and the ORR was $41.6 \%$ (95\% CI, 32.9-50.8). The median duration of response was 8.2, 9.3, and 6.5 months, respectively. After medication follow-up for a median of 14.8 months, the median OS was 8.8 months. Transfusion independence was attained in $35 \%$ of cases. Importantly, $88 \%$ of patients who achieved CR showed MRD negativity and $41 \%$ showed IDH1 mutation clearance. Thus, ivosidenib achieved reliable response and MRD negativity in older high-risk AML patients with IDH1 mutations. This trial led to FDA approval of ivosidenib in R/R AML patients with IDH1 mutations.

Another study compared clinical outcomes in the ivosidenib group and historical control group in R/R AML patients with IDH1 mutations [84]. In total, 109 patients in the ivosidenib group were compared to 60 in the control group. Median OS was 8.1 months in the ivosidenib group compared with 2.9 months in the control group $(p<0.0001)$. The 6- and 12-month survival rates in the ivosidenib group were $57.7 \%$ (95\% CI: 48.2, 67.2) and $35.0 \%$ (95\% CI: 25.7, 44.3), respectively, while the survival rates in the control group were $29.1 \%$ (95\% CI: $17.4,40.8)$ and $10.8 \%(95 \%$ CI: $2.7,18.9)$. The CR rate was also higher in the ivosidenib group $(18.3 \%, 95 \%$ CI: $11.6,26.9)$, compared to the control group $(7.0 \%$, $95 \%$ CI: $1.5,19.1)$. Ivosidenib monotherapy was associated with prolonged OS and the potential to increase $\mathrm{CR}$ rates vs. standard of care therapies in the control group.

The clinical benefit of ivosidenib combined with other agents is currently being evaluated in the randomized phase 3 trials.

\section{Hedgehog Signaling Pathway}

\subsection{Mechanism of Action}

The hedgehog $(\mathrm{HH})$ /glioma-associated oncogene homolog (GLI) signaling pathway is essential for embryonic development and is usually silenced in adult tissue [85]. Aberrant activation of HH/GLI signaling may play a major role in several cancers since it leads to genomic instability, proliferative signaling, replicative immortality, tumor invasionmetastasis, inflammation, and immune-surveillance evasion [86-90]. Aberrant activation of the HH/GLI pathway may result from both ligand-dependent and -independent mechanisms. In ligand-dependent activation, the so-called canonical HH/GLI pathway directly stimulates malignant cells [86]. The binding of processed and posttranslationally modified $\mathrm{HH}$ protein to its receptor, $\mathrm{PTCH}$, abolishes the inhibitory effect of $\mathrm{PTCH}$ on SMO, allowing ciliary transport and activation of SMO. GLI zinc finger transcription factors (GLI1, GLI2, and GLI3) are activated by SMO activation, and activated GLI is translocated into the nucleus and binds to the target DNA of the promoter, leading to the expression of specific genes, such as those encoding C-MYC, BCL-2, and SNAIL. Suppressor of fused (SUFU) is one element in the canonical HH pathway that downregulates GLI1-mediated target genes. When the GLI activator is promoted by SMO, it is translocated to the nucleus, leading to induction of $\mathrm{HH}$ target gene expression.

Meanwhile, ligand-independent HH/GLI signaling activation is mediated by PTCH loss-of-function or SUFU protein mutations, gain-of-function SMO mutations, or SMOindependent GLI activation through PI3K/AKT and RAS/RAF/MEK/ERK signaling [91]. Ligand-independent activation is considered the noncanonical means of $\mathrm{HH}$ pathway activation. Gene amplification or frameshift mutations finally result in abnormal GLI expression and function [92].

Overall, the HH/GLI signaling pathway is essential to hematopoietic stem cell function. Both $\mathrm{HH}$ and the signal transducer SMO are expressed in CD34+ AML cells. The 
$\mathrm{HH} / \mathrm{GLI}$ signaling pathway is significantly associated with the resistance of AML cells to standard chemotherapy (Figure 1).

\subsection{Glasdegib, HH/GLI Signal Pathway Inhibitor Clinical Data}

Glasdegib is a potent and selective oral inhibitor of the HH/GLI signaling pathway that acts by binding to SMO [93]. In preclinical studies, glasdegib, as a single agent or in combination with chemotherapy, was shown to reduce the expression of key leukemia stem cell regulators and decrease leukemia stem cell populations in patient-derived AML cells $[93,94]$.

In Table 2, a randomized, open-label, multicenter study evaluated the efficacy of glasdegib plus LDAC in patients with AML or high-risk MDS who were unfit for intensive chemotherapy [95]. Glasdegib $100 \mathrm{mg}$ was administered continuously in 28-day cycles and LDAC $20 \mathrm{mg}$ SC twice/day was administered for 10 per 28 days. The patients, who were stratified by cytogenetic risk, were randomized (2:1) to receive glasdegib plus LDAC $(n=88)$ or LDAC $(n=44)$. Median OS was 8.8 months (range, 6.9-9.9 months) in the glasdegib plus LDAC group and 4.9 months (range, 3.5-6.0 months) in the LDAC group (HR, 0.51; $80 \% \mathrm{CI}, 0.39-0.67, p=0.0004)$. The CR rate was $17 \%$ in the gladegib plus LDAC group $(n=17)$, compared to $2.3 \%(n=1)$ in the LDAC group $(p<0.05)$. Nonhematologic grade 3 or 4 adverse events included pneumonia $(16.7 \%)$ and fatigue $(14.3 \%)$ in the glasdegib plus LDAC group and pneumonia (14.6\%) in the LDAC group. Clinical efficacy was evident across patients with diverse mutational profiles. Thus, the data showed that glasdegib plus LDAC has a favorable benefit-risk profile and may be a promising option for AML patients unfit for intensive chemotherapy.

The above clinical phase II trial led to FDA approval of the agent as a therapeutic option in newly diagnosed AML patients who are older than 75 years of age or who have comorbidities that make them unsuitable for intensive chemotherapy.

\section{Conclusions}

The standard treatment for AML includes intensive chemotherapy, followed by postremission consolidation therapy with HSCT or chemotherapy. However, the modern management of AML has been significantly improved by the availability of novel targeted agents, such as an anti-CD33 monoclonal antibody, a BCL-2 inhibitor (venetoclax), FLT3 inhibitors (midostaurin, quizartinib, and gilteritinib), and IDH1/2 inhibitors (ivosidenib and enasidenib). Thus, as our understanding of the molecular biology of AML improves, it may be possible to predict targetable and novel prognostic subpopulations.

GO should be considered in cases of newly diagnosed or R/R CD33+ AML with favorable or intermediate-risk cytogenetics. GO could improve OS when added to intensive chemotherapy. Screenings for FLT3 and IDH1/2 mutations are recommended at both the diagnosis and relapse stages because patients with any of these mutations will benefit from the incorporation of targeted FLT3 inhibitors and IDH1/2 inhibitors. Particularly in elderly patients unfit for intensive chemotherapy, combination therapy with venetoclax and HMA/LDAC or the HH/GLI signaling pathway inhibitor glasdegib is a potential therapeutic option.

Currently, the application of NGS at diagnosis to investigate AML-associated mutations is increasingly recognized as means of refining the clinical outcome of the patients, identifying biomarkers of therapeutic response, and selecting patients who may benefit from novel targeted therapies.

Indeed, the increased diversity of therapeutic options requires a distinctive treatment algorithm that incorporates mutation-specific targeted therapies, monoclonal antibodies, and apoptosis-inducing small molecules. In this review, we anticipate that the use of a novel approved targeted agent could lead to improvement in clinical outcomes in patients with AML. Further well-designed clinical studies could address the mechanisms and clinical evidence of efficacy and safety of the targeted agents in patients with special conditions. 
Funding: This research received no external funding.

Informed Consent Statement: Not applicable.

Conflicts of Interest: The authors declare no conflict of interest.

\section{References}

1. Medinger, M.; Passweg, J.R. Acute myeloid leukaemia genomics. Br. J. Haematol. 2017, 179, 530-542. [CrossRef] [PubMed]

2. Pulte, D.; Gondos, A.; Brenner, H. Expected long-term survival of patients diagnosed with acute myeloblastic leukemia during 2006-2010. Ann. Oncol. 2009, 21, 335-341. [CrossRef] [PubMed]

3. Appelbaum, F.R.; Gundacker, H.; Head, D.R.; Slovak, M.L.; Willman, C.L.; Godwin, J.E.; Anderson, J.E.; Petersdorf, S.H. Age and acute myeloid leukemia. Blood 2006, 107, 3481-3485. [CrossRef] [PubMed]

4. Chen, K.T.J.; Gilabert-Oriol, R.; Bally, M.B.; Leung, A.W.Y. Recent Treatment Advances and the Role of Nanotechnology, Combination Products, and Immunotherapy in Changing the Therapeutic Landscape of Acute Myeloid Leukemia. Pharm. Res. 2019, 36, 1-20. [CrossRef]

5. Perl, A.E. The role of targeted therapy in the management of patients with AML. Blood Adv. 2017, 1, 2281-2294. [CrossRef]

6. Döhner, H.; Estey, E.; Grimwade, D.; Amadori, S.; Appelbaum, F.R.; Büchner, T.; Dombret, H.; Ebert, B.L.; Fenaux, P.; Larson, R.A.; et al. Diagnosis and management of AML in adults: 2017 ELN recommendations from an international expert panel. Blood 2017, 129, 424-447. [CrossRef]

7. Herold, T.; Rothenberg-Thurley, M.; Grunwald, V.V.; Janke, H.; Goerlich, D.; Sauerland, M.C.; Konstandin, N.P.; Dufour, A.; Schneider, S.; Neusser, M.; et al. Validation and refinement of the revised 2017 European LeukemiaNet genetic risk stratification of acute myeloid leukemia. Leukemia 2020, 34, 3161-3172. [CrossRef]

8. Kantarjian, H.M.; Thomas, X.G.; Dmoszynska, A.; Wierzbowska, A.; Mazur, G.; Mayer, J.; Gau, J.-P.; Chou, W.-C.; Buckstein, R.; Cermak, J.; et al. Multicenter, Randomized, Open-Label, Phase III Trial of Decitabine Versus Patient Choice, With Physician Advice, of Either Supportive Care or Low-Dose Cytarabine for the Treatment of Older Patients with Newly Diagnosed Acute Myeloid Leukemia. J. Clin. Oncol. 2012, 30, 2670-2677. [CrossRef]

9. Dombret, H.; Seymour, J.F.; Butrym, A.; Wierzbowska, A.; Selleslag, D.; Jang, J.H.; Kumar, R.; Cavenagh, J.D.; Schuh, A.C.; Candoni, A.; et al. International phase 3 study of azacitidine vs conventional care regimens in older patients with newly diagnosed AML with $>30 \%$ blasts. Blood 2015, 126, 291-299. [CrossRef]

10. Dick, J.E.; Lapidot, T. Biology of Normal and Acute Myeloid Leukemia Stem Cells. Int. J. Hematol. 2005, 82, 389-396. [CrossRef]

11. Deschler, B.; Lübbert, M. Acute myeloid leukemia: Epidemiology and etiology. Cancer 2006, 107, 2099-2107. [CrossRef]

12. Lawrence, M.S.; Stojanov, P.; Mermel, C.H.; Robinson, J.T.; Garraway, L.A.; Golub, T.R.; Meyerson, M.; Gabriel, S.B.; Lander, E.S.; Getz, G. Discovery and saturation analysis of cancer genes across 21 tumour types. Nature 2014, 505, 495-501. [CrossRef]

13. Lawrence, M.S.; Stojanov, P.; Polak, P.; Kryukov, G.V.; Cibulskis, K.; Sivachenko, A.; Carter, S.L.; Stewart, C.; Mermel, C.H.; Roberts, S.A.; et al. Mutational heterogeneity in cancer and the search for new cancer-associated genes. Nat. Cell Biol. 2013, 499, 214-218. [CrossRef]

14. Mardis, E.R.; Ding, L.; Dooling, D.J.; Larson, D.E.; McLellan, M.D.; Chen, K.; Koboldt, D.C.; Fulton, R.S.; Delehaunty, K.D.; McGrath, S.D.; et al. Recurring Mutations Found by Sequencing an Acute Myeloid Leukemia Genome. N. Engl. J. Med. 2009, 361, 1058-1066. [CrossRef]

15. Papaemmanuil, E.; Gerstung, M.; Bullinger, L.; Gaidzik, V.I.; Paschka, P.; Roberts, N.D.; Potter, N.E.; Heuser, M.; Thol, F.; Bolli, N.; et al. Genomic Classification and Prognosis in Acute Myeloid Leukemia. N. Engl. J. Med. 2016, 374, 2209-2221. [CrossRef]

16. Döhner, H.; Weisdorf, D.J.; Bloomfield, C.D. Acute Myeloid Leukemia. N. Engl. J. Med. 2015, 373, 1136-1152. [CrossRef]

17. Ley, T.J.; Miller, C.; Ding, L.; Raphael, B.J.; Mungall, A.J.; Robertson, A.G.; Hoadley, K.; Triche, T.J., Jr.; Laird, P.W.; Batym, J.D.; et al. Genomic and epigenomic landscapes of adult de novo acute myeloid leukemia. N. Engl. J. Med. 2013, 368, 2059-2074.

18. Ley, T.J.; Ding, L.; Walter, M.J.; McLellan, M.D.; Lamprecht, T.; Larson, D.E.; Kandoth, C.; Payton, J.E.; Baty, J.; Welch, J.; et al. DNMT3A mutations in acute myeloid leukemia. N. Engl. J. Med. 2010, 363, 2424-2433. [CrossRef]

19. Yan, X.-J.; Xu, J.; Gu, Z.-H.; Pan, C.-M.; Lu, G.; Shen, Y.; Shi, J.-Y.; Zhu, Y.-M.; Tang, L.; Zhang, X.-W.; et al. Exome sequencing identifies somatic mutations of DNA methyltransferase gene DNMT3A in acute monocytic leukemia. Nat. Genet. 2011, 43, 309-315. [CrossRef]

20. Ding, L.; Ley, T.J.; Larson, D.E.; Miller, C.A.; Koboldt, D.C.; Welch, J.S.; Ritchey, J.K.; Young, M.A.; Lamprecht, T.L.; McLellan, M.D.; et al. Clonal evolution in relapsed acute myeloid leukaemia revealed by whole-genome sequencing. Nat. Cell Biol. 2012, 481, 506-510. [CrossRef]

21. Patel, J.P.; Gönen, M.; Figueroa, M.E.; Fernandez, H.; Sun, Z.; Racevskis, J.; Van Vlierberghe, P.; Dolgalev, I.; Thomas, S.; Aminova, O.; et al. Prognostic Relevance of Integrated Genetic Profiling in Acute Myeloid Leukemia. N. Engl. J. Med. 2012, 366, 1079-1089. [CrossRef]

22. Welch, J.S.; Ley, T.J.; Link, D.C.; Miller, C.A.; Larson, D.E.; Koboldt, D.C.; Wartman, L.D.; Lamprecht, T.L.; Liu, F.; Xia, J.; et al. The origin and evolution of mutations in acute myeloid leukemia. Cell 2012, 150, 264-278. [CrossRef]

23. Schlenk, R.F.; Kayser, S.; Bullinger, L.; Kobbe, G.; Casper, J.; Ringhoffer, M.; Held, G.; Brossart, P.; Lübbert, M.; Salih, H.R.; et al. Differential impact of allelic ratio and insertion site in FLT3-ITD-positive AML with respect to allogeneic transplantation. Blood 2014, 124, 3441-3449. [CrossRef] 
24. Hamann, P.R.; Hinman, L.M.; Hollander, I.; Beyer, C.F.; Lindh, D.; Holcomb, R.; Hallett, W.; Tsou, H.-R.; Upeslacis, J.; Shochat, D.; et al. Gemtuzumab Ozogamicin, A Potent and Selective Anti-CD33 Antibody-Calicheamicin Conjugate for Treatment of Acute Myeloid Leukemia. Bioconjugate Chem. 2002, 13, 47-58. [CrossRef]

25. Paul, S.P.; Taylor, L.S.; Stansbury, E.K.; McVicar, D.W. Myeloid specific human CD33 is an inhibitory receptor with differential ITIM function in recruiting the phosphatases SHP-1 and SHP-2. Blood 2000, 96, 483-490. [CrossRef]

26. Appelbaum, F.R.; Bernstein, I.D. Gemtuzumab ozogamicin for acute myeloid leukemia. Blood 2017, 130, 2373-2376. [CrossRef]

27. Sievers, E.L.; Appelbaum, F.R.; Spielberger, R.T.; Forman, S.J.; Flowers, D.; Smith, F.O.; Shannon-Dorcy, K.; Berger, M.S.; Bernstein, I.D. Selective ablation of acute myeloid leukemia using antibody-targeted chemotherapy: A phase I study of an anti-CD33 calicheamicin immunoconjugate. Blood 1999, 93, 3678-3684. [CrossRef]

28. Zein, N.; Sinha, A.M.; McGahren, W.J.; A Ellestad, G. Calicheamicin gamma 1I: An antitumor antibiotic that cleaves doublestranded DNA site specifically. Science 1988, 240, 1198-1201. [CrossRef]

29. Rosen, D.B.; Harrington, K.H.; Cordeiro, J.A.; Leung, L.Y.; Putta, S.; Lacayo, N.; Laszlo, G.S.; Gudgeon, C.J.; Hogge, D.E.; Hawtin, R.E.; et al. AKT Signaling as a Novel Factor Associated with In Vitro Resistance of Human AML to Gemtuzumab Ozogamicin. PLoS ONE 2013, 8, e53518. [CrossRef]

30. Linenberger, M.L. CD33-directed therapy with gemtuzumab ozogamicin in acute myeloid leukemia: Progress in understanding cytotoxicity and potential mechanisms of drug resistance. Leukemia 2004, 19, 176-182. [CrossRef]

31. Amico, D.; Barbui, A.M.; Erba, E.; Rambaldi, A.; Introna, M.; Golay, J.T. Differential response of human acute myeloid leukemia cells to gemtuzumab ozogamicin in vitro: Role of Chk1 and Chk2 phosphorylation and caspase 3. Blood 2003, 101, $4589-4597$. [CrossRef] [PubMed]

32. Sievers, E.L.; Larson, R.; Stadtmauer, E.A.; Estey, E.; Löwenberg, B.; Dombret, H.; Karanes, C.; Theobald, M.; Bennett, J.M.; Sherman, M.L.; et al. Efficacy and Safety of Gemtuzumab Ozogamicin in Patients with CD33-Positive Acute Myeloid Leukemia in First Relapse. J. Clin. Oncol. 2001, 19, 3244-3254. [CrossRef] [PubMed]

33. Petersdorf, S.H.; Kopecky, K.J.; Slovak, M.; Willman, C.; Nevill, T.; Brandwein, J.; Larson, R.; Erba, H.P.; Stiff, P.J.; Stuart, R.K.; et al. A phase 3 study of gemtuzumab ozogamicin during induction and postconsolidation therapy in younger patients with acute myeloid leukemia. Blood 2013, 121, 4854-4860. [CrossRef] [PubMed]

34. Burnett, A.K.; Russell, N.H.; Hills, R.; Hunter, A.E.; Kjeldsen, L.; Yin, J.; Gibson, B.E.; Wheatley, K.; Milligan, D. Optimization of Chemotherapy for Younger Patients with Acute Myeloid Leukemia: Results of the Medical Research Council AML15 Trial. J. Clin. Oncol. 2013, 31, 3360-3368. [CrossRef] [PubMed]

35. Burnett, A.K.; Hills, R.; Milligan, D.; Kjeldsen, L.; Kell, J.; Russell, N.H.; Yin, J.A.; Hunter, A.; Goldstone, A.H.; Wheatley, K. Identification of Patients with Acute Myeloblastic Leukemia Who Benefit from the Addition of Gemtuzumab Ozogamicin: Results of the MRC AML15 Trial. J. Clin. Oncol. 2011, 29, 369-377. [CrossRef] [PubMed]

36. Castaigne, S.; Pautas, C.; Terré, C.; Raffoux, E.; Bordessoule, D.; Bastie, J.-N.; Legrand, O.; Thomas, X.; Turlure, P.; Reman, O.; et al. Effect of gemtuzumab ozogamicin on survival of adult patients with de-novo acute myeloid leukaemia (ALFA-0701): A randomised, open-label, phase 3 study. Lancet 2012, 379, 1508-1516. [CrossRef]

37. Hills, R.K.; Castaigne, S.; Appelbaum, F.R.; Delaunay, J.; Petersdorf, S.; Othus, M.; Estey, E.H.; Dombret, H.; Chevret, S.; Ifrah, N.; et al. Addition of gemtuzumab ozogamicin to induction chemotherapy in adult patients with acute myeloid leukaemia: A meta-analysis of individual patient data from randomised controlled trials. Lancet Oncol. 2014, 15, 986-996. [CrossRef]

38. Burnett, A.; Cavenagh, J.; Russell, N.; Hills, R.; Kell, J.; Jones, G.; Nielsen, O.J.; Khwaja, A.; Thomas, I.; Clark, R.; et al. Defining the dose of gemtuzumab ozogamicin in combination with induction chemotherapy in acute myeloid leukemia: A comparison of $3 \mathrm{mg} / \mathrm{m} 2$ with $6 \mathrm{mg} / \mathrm{m} 2$ in the NCRI AML17 Trial. Haematology 2016, 101, 724-731. [CrossRef]

39. Amadori, S.; Suciu, S.; Selleslag, D.; Aversa, F.; Gaidano, G.; Musso, M.; Annino, L.; Venditti, A.; Voso, M.T.; Mazzone, C.; et al. Gemtuzumab Ozogamicin Versus Best Supportive Care in Older Patients with Newly Diagnosed Acute Myeloid Leukemia Unsuitable for Intensive Chemotherapy: Results of the Randomized Phase III EORTC-GIMEMA AML-19 Trial. J. Clin. Oncol. 2016, 34, 972-979. [CrossRef]

40. Cheng, E.H.; Wei, M.C.; Weiler, S.; Flavell, R.A.; Mak, T.W.; Lindsten, T.; Korsmeyer, S.J. BCL-2, BCL-X(L) sequester BH3 domain-only molecules preventing BAX- and BAK-mediated mitochondrial apoptosis. Mol. Cell. 2001, 8, 705-711. [CrossRef]

41. Wei, A.H.; Strickland, S.A., Jr.; Hou, J.Z.; Fiedler, W.; Lin, T.L.; Walter, R.B.; Enjeti, A.; Tiong, I.S.; Savona, M.; Lee, S.; et al. Venetoclax Combined with Low-Dose Cytarabine for Previously Untreated Patients with Acute Myeloid Leukemia: Results from a Phase Ib/II Study. J. Clin. Oncol. 2019, 37, 1277-1284. [CrossRef]

42. Dinardo, C.D.; Pratz, K.; Pullarkat, V.; Jonas, B.A.; Arellano, M.; Becker, P.S.; Frankfurt, O.; Konopleva, M.; Wei, A.H.; Kantarjian, H.M.; et al. Venetoclax combined with decitabine or azacitidine in treatment-naive, elderly patients with acute myeloid leukemia. Blood 2019, 133, 7-17. [CrossRef]

43. Bogenberger, J.M.; Delman, D.; Hansen, N.; Valdez, R.; Fauble, V.; Mesa, R.A.; Tibes, R. Ex vivo activity of BCL-2 family inhibitors ABT-199 and ABT-737 combined with 5-azacytidine in myeloid malignancies. Leuk. Lymphoma 2015, 56, 226-229. [CrossRef]

44. Tsao, T.; Shi, Y.; Kornblau, S.; Lu, H.; Konoplev, S.; Antony, A.; Ruvolo, V.; Qiu, Y.H.; Zhang, N.; Coombes, K.R.; et al. Concomitant inhibition of DNA methyltransferase and BCL-2 protein function synergistically induce mitochondrial apoptosis in acute myelogenous leukemia cells. Ann. Hematol. 2012, 91, 1861-1870. [CrossRef] 
45. Dinardo, C.D.; Jonas, B.A.; Pullarkat, V.; Thirman, M.J.; Garcia, J.S.; Wei, A.H.; Konopleva, M.; Döhner, H.; Letai, A.; Fenaux, P.; et al. Azacitidine and Venetoclax in Previously Untreated Acute Myeloid Leukemia. N. Engl. J. Med. 2020, 383, 617-629. [CrossRef]

46. Wei, A.H.; Montesinos, P.; Ivanov, V.; Dinardo, C.D.; Novak, J.; Laribi, K.; Kim, I.; Stevens, D.A.; Fiedler, W.; Pagoni, M.; et al. Venetoclax plus LDAC for newly diagnosed AML ineligible for intensive chemotherapy: A phase 3 randomized placebo-controlled trial. Blood 2020, 135, 2137-2145. [CrossRef]

47. Lyman, S.D.; James, L.; Bos, T.V.; de Vries, P.; Brasel, K.; Gliniak, B.; Hollingsworth, L.T.; Picha, K.S.; McKenna, H.J.; Splett, R.R.; et al. Molecular cloning of a ligand for the flt3/flk-2 tyrosine kinase receptor: A proliferative factor for primitive hematopoietic cells. Cell 1993, 75, 1157-1167. [CrossRef]

48. Nakao, M.; Yokota, S.; Iwai, T.; Kaneko, H.; Horiike, S.; Kashima, K.; Sonoda, Y.; Fujimoto, T.; Misawa, S. Internal tandem duplication of the flt3 gene found in acute myeloid leukemia. Leukemia 1996, 10, 1911-1918.

49. Yamamoto, Y.; Kiyoi, H.; Nakano, Y.; Suzuki, R.; Kodera, Y.; Miyawaki, S.; Asou, N.; Kuriyama, K.; Yagasaki, F.; Shimazaki, C.; et al. Activating mutation of D835 within the activation loop of FLT3 in human hematologic malignancies. Blood 2001, 97, 2434-2439. [CrossRef]

50. Gilliland, D.G.; Griffin, J.D. The roles of FLT3 in hematopoiesis and leukemia. Blood 2002, 100, 1532-1542. [CrossRef]

51. Choudhary, C.; Olsen, J.V.; Brandts, C.; Cox, J.; Reddy, P.N.; Böhmer, F.D.; Gerke, V.; Schmidt-Arras, D.-E.; Berdel, W.E.; MüllerTidow, C.; et al. Mislocalized Activation of Oncogenic RTKs Switches Downstream Signaling Outcomes. Mol. Cell 2009, 36, 326-339. [CrossRef]

52. Choudhary, C.; Schwaäble, J.; Brandts, C.; Tickenbrock, L.; Sargin, B.; Kindler, T.; Fischer, T.; Berdel, W.E.; Muüller-Tidow, C.; Serve, H. AML-associated Flt3 kinase domain mutations show signal transduction differences compared with Flt3 ITD mutations. Blood 2005, 106, 265-273. [CrossRef]

53. Okada, K.; Nogami, A.; Ishida, S.; Akiyama, H.; Chen, C.; Umezawa, Y.; Miura, O. FLT3-ITD induces expression of Pim kinases through STAT5 to confer resistance to the PI3K/Akt pathway inhibitors on leukemic cells by enhancing the mTORC1/Mcl-1 pathway. Oncotarget 2017, 9, 8870-8886. [CrossRef]

54. Bagrintseva, K.; Geisenhof, S.; Kern, R.; Eichenlaub, S.; Reindl, C.; Ellwart, J.W.; Hiddemann, W.; Spiekermann, K. FLT3-ITD-TKD dual mutants associated with AML confer resistance to FLT3 PTK inhibitors and cytotoxic agents by overexpression of Bcl-x(L). Blood 2005, 105, 3679-3685. [CrossRef]

55. Port, M.; Böttcher, M.; Thol, F.; Ganser, A.; Schlenk, R.; Wasem, J.; Neumann, A.; Pouryamout, L. Prognostic significance of FLT3 internal tandem duplication, nucleophosmin 1, and CEBPA gene mutations for acute myeloid leukemia patients with normal karyotype and younger than 60 years: A systematic review and meta-analysis. Ann. Hematol. 2014, 93, 1279-1286. [CrossRef]

56. Weisberg, E.; Boulton, C.; Kelly, L.M.; Manley, P.; Fabbro, D.; Meyer, T.; Gilliland, D.; Griffin, J.D. Inhibition of mutant FLT3 receptors in leukemia cells by the small molecule tyrosine kinase inhibitor PKC412. Cancer Cell 2002, 1, 433-443. [CrossRef]

57. Levis, M. Midostaurin approved for FLT3-mutated AML. Blood 2017, 129, 3403-3406. [CrossRef]

58. Stone, R.M.; Fischer, T.; Paquette, R.; Schiller, G.; A Schiffer, C.; Ehninger, G.; Cortes, J.; Kantarjian, H.M.; DeAngelo, D.J.; Huntsman-Labed, A.; et al. Phase IB study of the FLT3 kinase inhibitor midostaurin with chemotherapy in younger newly diagnosed adult patients with acute myeloid leukemia. Leukemia 2012, 26, 2061-2068. [CrossRef]

59. Stone, R.M.; Mandrekar, S.J.; Sanford, B.L.; Laumann, K.; Geyer, S.; Bloomfield, C.D.; Thiede, C.; Prior, T.W.; Döhner, K.; Marcucci, G.; et al. Midostaurin plus Chemotherapy for Acute Myeloid Leukemia with a FLT3 Mutation. N. Engl. J. Med. 2017, 377, 454-464. [CrossRef]

60. Levis, M. Quizartinib for the treatment of FLT3/ITD acute myeloid leukemia. Futur. Oncol. 2014, 10, 1571-1579. [CrossRef]

61. Cortes, J.E.; Kantarjian, H.; Foran, J.M.; Ghirdaladze, D.; Zodelava, M.; Borthakur, G.; Gammon, G.; Trone, D.; Armstrong, R.C.; James, J.; et al. Phase I Study of Quizartinib Administered Daily to Patients with Relapsed or Refractory Acute Myeloid Leukemia Irrespective of FMS-Like Tyrosine Kinase 3-Internal Tandem Duplication Status. J. Clin. Oncol. 2013, 31, 3681-3687. [CrossRef] [PubMed]

62. Cortes, J.; E Perl, A.; Döhner, H.; Kantarjian, H.; Martinelli, G.; Kovacsovics, T.; Rousselot, P.; Steffen, B.; Dombret, H.; Estey, E.; et al. Quizartinib, an FLT3 inhibitor, as monotherapy in patients with relapsed or refractory acute myeloid leukaemia: An open-label, multicentre, single-arm, phase 2 trial. Lancet Oncol. 2018, 19, 889-903. [CrossRef]

63. Cortes, J.E.; Khaled, S.; Martinelli, G.; Perl, A.E.; Ganguly, S.; Russell, N.; Krämer, A.; Dombret, H.; Hogge, D.; Jonas, B.A.; et al. Quizartinib versus salvage chemotherapy in relapsed or refractory FLT3-ITD acute myeloid leukaemia (QuANTUM-R): A multicentre, randomised, controlled, open-label, phase 3 trial. Lancet Oncol. 2019, 20, 984-997. [CrossRef]

64. Lee, L.Y.; Hernandez, D.; Rajkhowa, T.; Smith, S.C.; Raman, J.R.; Nguyen, B.; Small, D.; Levis, M. Preclinical studies of gilteritinib, a next-generation FLT3 inhibitor. Blood 2017, 129, 257-260. [CrossRef] [PubMed]

65. Perl, A.E.; Altman, J.K.; Cortes, J.; Smith, C.; Litzow, M.; Baer, M.R.; Claxton, D.; Erba, H.P.; Gill, S.; Goldberg, S.; et al. Selective inhibition of FLT3 by gilteritinib in relapsed or refractory acute myeloid leukaemia: A multicentre, first-in-human, open-label, phase 1-2 study. Lancet Oncol. 2017, 18, 1061-1075. [CrossRef]

66. Perl, A.E.; Martinelli, G.; Cortes, J.; Neubauer, A.; Berman, E.; Paolini, S.; Montesinos, P.; Baer, M.R.; Larson, R.A.; Ustun, C.; et al. Gilteritinib or Chemotherapy for Relapsed or Refractory FLT3-Mutated AML. N. Engl. J. Med. 2019, 381, 1728-1740. [CrossRef]

67. Reitman, Z.J.; Yan, H. Isocitrate Dehydrogenase 1 and 2 Mutations in Cancer: Alterations at a Crossroads of Cellular Metabolism. J. Natl. Cancer Inst. 2010, 102, 932-941. [CrossRef] 
68. Ward, P.S.; Patel, J.; Wise, D.R.; Abdel-Wahab, O.; Bennett, B.D.; Coller, H.A.; Cross, J.R.; Fantin, V.R.; Hedvat, C.V.; Perl, A.E.; et al. The common feature of leukemia-associated IDH1 and IDH2 mutations is a neomorphic enzyme activity converting alpha-ketoglutarate to 2-hydroxyglutarate. Cancer Cell 2010, 17, 225-234. [CrossRef]

69. Rakheja, D.; Medeiros, L.J.; Bevan, S.; Chen, W. The emerging role of d-2-hydroxyglutarate as an oncometabolite in hematolymphoid and central nervous system neoplasms. Front. Oncol. 2013, 3, 169. [CrossRef]

70. Hou, W.-C.; Lei, W.-C.; Ko, B.-S.; Hou, H.-A.; Chen, C.-Y.; Tang, J.-L.; Yao, M.; Tsay, W.; Wu, S.-J.; Huang, S.-Y.; et al. The prognostic impact and stability of Isocitrate dehydrogenase 2 mutation in adult patients with acute myeloid leukemia. Leukemia 2010, 25, 246-253. [CrossRef]

71. Chou, W.-C.; Hou, H.-A.; Chen, C.-Y.; Tang, J.-L.; Yao, M.; Tsay, W.; Ko, B.-S.; Wu, S.-J.; Huang, S.-Y.; Hsu, S.-C.; et al. Distinct clinical and biologic characteristics in adult acute myeloid leukemia bearing the isocitrate dehydrogenase 1 mutation. Blood 2010, 115, 2749-2754. [CrossRef]

72. Thol, F.; Damm, F.; Wagner, K.; Göhring, G.; Schlegelberger, B.; Hoelzer, D.; Lübbert, M.; Heit, W.; Kanz, L.; Schlimok, G.; et al. Prognostic impact of IDH2 mutations in cytogenetically normal acute myeloid leukemia. Blood 2010, 116, 614-616. [CrossRef]

73. Fathi, A.T.; Sadrzadeh, H.; Borger, D.R.; Ballen, K.K.; Amrein, P.C.; Attar, E.C.; Foster, J.; Burke, M.; Lopez, H.U.; Matulis, C.R.; et al. Prospective serial evaluation of 2-hydroxyglutarate, during treatment of newly diagnosed acute myeloid leukemia, to assess disease activity and therapeutic response. Blood 2012, 120, 4649-4652. [CrossRef]

74. Abbas, S.; Lugthart, S.; Kavelaars, F.; Schelen, A.; Koenders, J.; Zeilemaker, A.; Van Putten, W.J.L.; Rijneveld, A.; Löwenberg, B.; Valk, P. Acquired mutations in the genes encoding IDH1 and IDH2 both are recurrent aberrations in acute myeloid leukemia: Prevalence and prognostic value. Blood 2010, 116, 2122-2126. [CrossRef]

75. Medeiros, B.C.; Fathi, A.T.; DiNardo, C.D.; Pollyea, D.A.; Chan, S.M.; Swords, R. Isocitrate dehydrogenase mutations in myeloid malignancies. Leukemia 2017, 31, 272-281. [CrossRef]

76. Dhillon, S. Ivosidenib: First Global Approval. Drugs 2018, 78, 1509-1516. [CrossRef]

77. Kim, E.S. Enasidenib: First Global Approval. Drugs 2017, 77, 1705-1711. [CrossRef]

78. Marcucci, G.; Maharry, K.; Wu, Y.-Z.; Radmacher, M.D.; Mrózek, K.; Margeson, D.; Holland, K.B.; Whitman, S.P.; Becker, H.; Schwind, S.; et al. IDH1andIDH2Gene Mutations Identify Novel Molecular Subsets Within De Novo Cytogenetically Normal Acute Myeloid Leukemia: A Cancer and Leukemia Group B Study. J. Clin. Oncol. 2010, 28, 2348-2355. [CrossRef]

79. Yen, K.; Travins, J.; Wang, F.; David, M.D.; Artin, E.; Straley, K.; Padyana, A.; Gross, S.; DelaBarre, B.; Tobin, E.; et al. AG-221, a First-in-Class Therapy Targeting Acute Myeloid Leukemia Harboring Oncogenic IDH2 Mutations. Cancer Discov. 2017, 7, 478-493. [CrossRef]

80. Stein, E.M.; Dinardo, C.D.; Pollyea, D.A.; Fathi, A.T.; Roboz, G.J.; Altman, J.K.; Stone, R.M.; DeAngelo, D.J.; Levine, R.L.; Flinn, I.W.; et al. Enasidenib in mutant IDH2 relapsed or refractory acute myeloid leukemia. Blood 2017, 130, 722-731. [CrossRef]

81. Klink, A.J.; Copher, R.; Knoth, R.L.; Marshall, L.; Hou, Y.; Gajra, A.; Tibes, R. Real-World Use of Enasidenib in Relapsed or Refractory Acute Myeloid Leukemia Is Associated with Reduced Risk of Disease Progression and Death. Blood 2020, $136,18$. [CrossRef]

82. Riva, M.; Rizzo, L.; Mancini, V.; Greco, R.; Bertani, G.; Zucchetti, E.; Diral, E.; Nichelatti, M.; Veronese, S.M.; Grillo, G.; et al. Enasidenib, an Oral Therapy in Mutant IDH2 Relapsed/Refractory Acute Myeloid Leukemia: A Real-Life Single Center Experience. Blood 2020, 136, 20-21. [CrossRef]

83. Dinardo, C.D.; Stein, E.M.; De Botton, S.; Roboz, G.J.; Altman, J.K.; Mims, A.S.; Swords, R.; Collins, R.H.; Mannis, G.N.; Pollyea, D.A.; et al. Durable Remissions with Ivosidenib inIDH1-Mutated Relapsed or Refractory AML. N. Engl. J. Med. 2018, 378, 2386-2398. [CrossRef]

84. Paschka, P.; Dombret, H.; Thomas, X.; Recher, C.; Chantepie, S.; Fernandez, P.M.; Acuña-Cruz, E.; Vyas, M.P.; Kreuzer, K.-A.; Heuser, M.; et al. Ivosidenib Improves Overall Survival Relative to Standard Therapies in Relapsed or Refractory Mutant IDH1 AML: Results from Matched Comparisons to Historical Controls. Blood 2020, 136, 18-19. [CrossRef]

85. Gao, J.; Graves, S.; Koch, U.; Liu, S.; Jankovic, V.; Buonamici, S.; El Andaloussi, A.; Nimer, S.D.; Kee, B.L.; Taichman, R.S.; et al. Hedgehog Signaling Is Dispensable for Adult Hematopoietic Stem Cell Function. Cell Stem Cell 2009, 4, 548-558. [CrossRef]

86. Blotta, S.; Jakubikova, J.; Calimeri, T.; Roccaro, A.M.; Amodio, N.; Azab, A.K.; Foresta, U.; Mitsiades, C.S.; Rossi, M.; Todoerti, K.; et al. Canonical and noncanonical Hedgehog pathway in the pathogenesis of multiple myeloma. Blood 2012, 120, 5002-5013. [CrossRef]

87. Jagani, Z.; Dorsch, M.; Warmuth, M. Hedgehog pathway activation in chronic myeloid leukemia: A promise for a novel combination therapeutic approach? Cell Cycle 2010, 9, 3449-3456. [CrossRef] [PubMed]

88. Caro, I.; Low, J.A. The role of the hedgehog signaling pathway in the development of basal cell carcinoma and opportunities for treatment. Clin. Cancer Res. 2010, 16, 3335-3339. [CrossRef]

89. Romer, J.; Curran, T. Targeting medulloblastoma: Small-molecule inhibitors of the Sonic Hedgehog pathway as potential cancer therapeutics. Cancer Res. 2005, 65, 4975-4978. [CrossRef] [PubMed]

90. Justilien, V.; Walsh, M.P.; Ali, S.A.; Thompson, E.A.; Murray, N.R.; Fields, A.P. The PRKCI and SOX2 Oncogenes Are Coamplified and Cooperate to Activate Hedgehog Signaling in Lung Squamous Cell Carcinoma. Cancer Cell 2014, 25, 139-151. [CrossRef] [PubMed]

91. Aberger, F.; Kern, D.; Greil, R.; Hartmann, T.N. Canonical and noncanonical Hedgehog/GLI signaling in hematological malignancies. Vitam. Horm. 2012, 88, 25-54. 
92. Aszterbaum, M.; Rothman, A.; Johnson, R.L.; Fisher, M.; Xie, J.; Bonifas, J.M.; Zhang, X.; Scott, M.P.; Epstein, E.H., Jr. Identification of mutations in the human PATCHED gene in sporadic basal cell carcinomas and in patients with the basal cell nevus syndrome. J. Invest Dermatol. 1998, 110, 885-888. [CrossRef]

93. Fukushima, N.; Minami, Y.; Kakiuchi, S.; Kuwatsuka, Y.; Hayakawa, F.; Jamieson, C.; Kiyoi, H.; Naoe, T. Small-molecule Hedgehog inhibitor attenuates the leukemia-initiation potential of acute myeloid leukemia cells. Cancer Sci. 2016, 107, 1422-1429. [CrossRef]

94. Sadarangani, A.; Pineda, G.; Lennon, K.M.; Chun, H.-J.; Shih, A.; E Schairer, A.; Court, A.C.; Goff, D.J.; Prashad, S.L.; Geron, I.; et al. GLI2 inhibition abrogates human leukemia stem cell dormancy. J. Transl. Med. 2015, 13, 1-14. [CrossRef]

95. Cortes, J.E.; Heidel, F.H.; Hellmann, A.; Fiedler, W.; Smith, B.D.; Robak, T.; Montesinos, P.; Pollyea, D.A.; Desjardins, P.; Ottmann, O.; et al. Randomized comparison of low dose cytarabine with or without glasdegib in patients with newly diagnosed acute myeloid leukemia or high-risk myelodysplastic syndrome. Leukemia 2019, 33, 379-389. [CrossRef] 